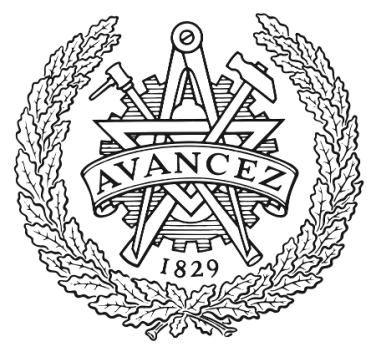

CHALMERS

UNIVERSITY OF TECHNOLOGY

\title{
Dynamic modeling for assessment of steam cycle operation in waste-fired combined heat and power plants
}

Downloaded from: https://research.chalmers.se, 2023-04-26 09:38 UTC

Citation for the original published paper (version of record):

Beiron, J., Mocholí Montañés, R., Normann, F. et al (2019). Dynamic modeling for assessment of steam cycle operation in waste-fired combined heat and power plants. Energy Conversion and Management, 198. http://dx.doi.org/10.1016/j.enconman.2019.111926

N.B. When citing this work, cite the original published paper. 


\title{
Dynamic modeling for assessment of steam cycle operation in waste- fired combined heat and power plants
}

\author{
Johanna Beiron*, Rubén M. Montañés, Fredrik Normann, Filip Johnsson \\ *Corresponding author: beiron@chalmers.se (J. Beiron) \\ Department of Space, Earth and Environment, Chalmers University of Technology, S-412 96 Göteborg, Sweden
}

Link to published article: https://doi.org/10.1016/j.enconman.2019.111926

Published in Energy Conversion and Management, Volume 198, 15 October 2019, 111926

\begin{abstract}
As the share of non-dispatchable energy sources in power systems increases, thermal power plants, are expected to experience load variations to a greater extent. Waste-fired combined heat and power has multiple products and is today primarily operated for waste incineration and to generate heat. To consider load variations in the power demand at these plants may be a way to provide system services and obtain revenue, however, the transient interaction between power and district heating generation for the type of steam systems used should be studied. This work describes the transient characteristics and timescales of cogeneration steam cycles to discuss the operational interactions between power and district heating generation. A dynamic model of the steam cycle of a $48 \mathrm{MW}$ waste-fired combined heat and power plant is developed using physical equations and the modeling language Modelica. The model is successfully validated quantitatively for both steady-state and transient operation with data from a reference plant and is shown capable of characterizing the internal dynamics of combined heat and power plant processes. Simulations are performed to analyze plant responses to step changes, ramps and sinusoidal disturbances of boiler load changes and variability in district heating inlet temperature and flow. The results give insight on the process timescales for the specific case studied; for example, with the present design a $10 \%$ boiler load change requires up to 15 minutes for responses to settle, while the corresponding time for a $10 \%$ change in district heating flow or temperature show settling times within 5 minutes. Furthermore, increasing the boiler ramp rate from 2 to $4 \% /$ min could reduce the rise time of power generation by $42 \%$, which could be of economic significance in day-ahead power markets.
\end{abstract}

\section{Highlights}

- A dynamic model of a cogeneration steam cycle is developed and validated.

- The effects of boiler load changes on power and heat generation are analyzed.

- Operational impacts of district heating disturbances are characterized.

\section{Keywords}

Combined Heat and Power; Dynamic Modeling; Modelica; Steam Cycle; District Heating; Flexibility 


\section{Nomenclature}

Greek

$\alpha \quad$ heat transfer coefficient

$\beta \quad$ Baumann factor

$\eta \quad$ efficiency

$\theta \quad$ valve opening

$\lambda$ thermal conductivity

$\rho$ density

$\psi \quad$ enhancement factor

\section{Latin}

A area, amplitude

Bo Boiling number

C calibration factor

Co Convection number

$\mathrm{C}_{\mathrm{v}} \quad$ valve flow coefficient

E energy

F correction factor

G mass flow density

$\mathrm{K}$ empirical parameter

$\mathrm{K}_{\mathrm{f}} \quad$ friction loss coefficient

$\mathrm{K}_{\mathrm{t}} \quad$ flow area coefficient

LF length fraction

$\mathrm{Nu} \quad$ Nusselt number

$\mathrm{P} \quad$ power

Pr Prandtl number

Q heat flow

$\mathrm{R} \quad$ ideal gas constant, resistance

$\mathrm{T}$ temperature

V volume

c heat capacity

d diameter

dp differential pressure

h enthalpy

$\mathrm{m}$ mass, mass flow

$\mathrm{n}$ number of

$\mathrm{p}$ pressure

q heat flux

s wall thickness

$\mathrm{t}$ time

$\mathrm{x} \quad$ steam quality

\section{Subscripts}

a area, arrangement

c condensate

emp empirical

fw feed water

g gas

is isentropic

$\mathrm{L}, 1$ liquid

LM Logarithmic Mean

$\begin{array}{ll}\text { mech } & \text { mechanical } \\ \text { nom } & \text { nominal } \\ \mathrm{p} & \text { pressure } \\ \mathrm{s} & \text { steam } \\ \text { surf } & \text { surface } \\ \text { tp } & \text { two phase } \\ \mathrm{v} & \text { vapor } \\ \text { vap } & \text { vaporization } \\ \text { vol } & \text { volume }\end{array}$

Abbreviations

AP Absolute Percentage Deviation

BB Boiler Bank

CCS Carbon Capture and Storage

CFB Circulating Fluidized Bed

CHP Combined Heat and Power

COND Condenser

DEA Deaerator

DH District Heating

ECO Economizer

GEN Generator

HP High-pressure

LHV Lower Heating Value

LP Low-pressure

LPFWH Low-Pressure Feed Water Heater

RA Relative Amplitude

RC Relative Change

RV Reference Value

SH Superheater

SV Simulated Value 


\section{Introduction}

With the expected increase of variable renewable energy (VRE) sources in the European electricity system, the operational flexibility of thermal power plants is likely to be challenged and require development [1]; indicating the importance to study the dynamic characteristics of these plants. In the Swedish power system context, all thermal power plants except nuclear; usually biomass or waste-fired, operate as cogeneration units, i.e. combined heat and power (CHP) plants. Traditionally these plants produce district heat (DH) for space heating as their main product or deliver steam to industrial processes. Cogeneration is energy efficient in the sense that there are small heat losses, with total plant LHV efficiencies typically above $90 \%$ (if assuming the same value of electricity and heat). Normally, DH is the plant's main product, given the large demand for space heating in the region, and the production is planned based on the heat demand profile [2]. Thus, although there may be market benefits related to operational strategies that consider the power demand profile to a greater extent, opportunities to implement such measures may be limited by the need for stable delivery of DH. To find strategies for flexible operation of CHP units in a way that does not overly interfere with requirements of DH delivery is therefore key and requires the study of the load changing characteristics and interaction with the DH network of such plant types. Current research directions and ideas for CHP flexibilization presented in literature include:

- Implementation of thermal energy storages for decoupling of heat and power production; internally in a gas-fired plant [3], and in district heating systems [4].

- Heat load control by interaction with CCS to allow decoupling of heat and power production, with focus on control schemes [5] and the effect of variations in available heat on capture plant performance [6].

- Primary frequency response potential of CHP plants [7].

- Operational flexibility for variable power-to-heat ratio; by turbine bypass [8] and operation in backpressure or extraction mode [9].

- Optimization of district heating systems and CHP plant dispatch [10].

- Polygeneration - using the boiler for gasification and biofuel production [11].

- Fuel flexibility [12].

Within flexibilization research, dynamic power plant models are powerful tools in the study and design of operational characteristics of power plants. Dynamic power plant models can be based on physical differential and algebraic equations that are used to describe the processes within the system being studied. An adequate representation of the system both enhances the understanding of the system and its dynamic characteristics, but also enables testing of new operational strategies and process configurations in a safe environment. A thorough review of state-of-the-art practices and principles is given in [13]. Previous work has, for example, focused on evaluation of operational strategies, implementation of control structures, model development, and developing methods for estimation of thermal stresses in gas combined cycles [14] and steam power plants [15], including superheater and drum [16] and headers [17].

Chen et al. [18] developed a dynamic model and studied the implementation of a regulatory control structure in a 605 MW coal-fired plant, followed up by development of dynamic supervisory control schemes for plant efficiency optimization [19]. Coal-fired plant responses to step and ramp changes in load were analyzed by Oko and Wang [20]. Furthermore, dynamic modeling for process monitoring purposes has been demonstrated [21]. Transient operation and control of power plants with CCS units has been investigated for gas-combined cycles [22] and coal-fired units [23], with a comparison of control strategies [24]. Nord and Montañés [25] developed dynamic process models of a compact combined cycle for offshore oil and gas installations, and evaluated the performance of several decentralized control structures under minute-timescale load changes. In addition, Montañés et al. [26] developed dynamic process models of a concentrated solar power plant with molten salts energy storage technology, with the purpose of analyzing and evaluating energy storage concepts and its interaction with the solar field and the steam cycle. Several platforms and simulation environments are available for dynamic modeling, of which Apros and Aspen Plus Dynamics were compared by Alobaid et al. [27]. Recently, attention has also been given to dynamic evaluation of plant flexibility measures, such as steam extraction regulation [28] including characterization of different regulation measures [29]; and high temperature thermal storage of steam [30]. The potential to use gas-fired industrial CHP plants for grid frequency services while 
maintaining a reliable delivery of process steam was studied by Kahlert and Spliethoff [7]. Experimental testing of municipal CHP plants' potential to fulfill requirements for participating in automatic frequency restoration reserve markets was also performed [31].

Clearly, several types of dynamic power plant models have been developed, although mainly focused on condensing plants that combust coal, gas or oil; with few studies concerning waste-fired cogeneration steam cycles. The fuel type may to some extent influence the plant design, and consequently also the dynamics. For instance, since waste is a low-cost fuel, and a primary objective of waste-fired plants is waste management; wastefired CHP steam cycles are typically designed for base-load operation, with low flexibility. This is also because CHP plants are traditionally dependent on heat delivery and are commonly operated all year around to provide heat for heating and for hot tap water. Nevertheless, there may be a potential for such CHP plants to provide flexibility services to the power system, such as load following operation or system services like frequency regulation.

Previous studies on waste-fired CHP plants have modeled the gas-side dynamics: Alobaid et al. [32] developed a model of a $60 \mathrm{MW}$ plant with detailed representation of the waste combustion process in a grate-fired CHP boiler. Zimmerman et al. [33] presented a model of a circulating fluidized bed (CFB) waste-fired CHP plant, for evaluation of model predictive control schemes. However, these works focus on the steam boiler, including combustion, and do not analyze in detail the steam cycle and district heating boundary. The transient interaction between the operation of steam cycles and district heating networks has thus, to the authors' knowledge, been peripheral.

This paper aims at characterizing the dynamics of heat and power generation in a waste-fired CHP plant steam cycle of medium size (167 MW thermal load), designed for base-load operation and waste incineration as a primary target. The operational performance of the plant, as influenced by variability in boiler load and district heating conditions, is simulated to identify and analyze the timescales of power and heat generation. For this purpose, a dynamic model of a waste-fired CHP steam cycle in a Nordic setting is developed and validated with steady-state and transient data, for use within the scope of the paper and as a basis for further study of the internal process dynamics of the plant. To put the study in perspective, the time-dependent aspects of flexible CHP steam cycle operation are discussed in relation to the district heating system and surrounding electricity system in terms of electricity price fluctuations.

\section{Methods}

The method followed in this work is summarized in Figure 1 and consists of three main parts: data acquisition, modeling and simulations of scenarios. The data acquisition serves as a foundation for the modeling. A suitable CHP plant is selected to act as a reference for the developed model - the reference plant is presented in Section 3 and a detailed description of the final model is given in Section 4. Operational and process data at different load conditions is used for steady-state validation and a targeted campaign is carried out at the plant to obtain transient validation data for a defined load cycle. The model validation for steady-state conditions and transient operation is presented in Section 5. Finally, scenarios are studied, in which the model is used to simulate the dynamics of boundary condition disturbances and the respective impact on process performance. Three input variables are chosen as disturbances:

- Boiler load level

- District heating flow rate

- District heating inlet temperature

In the model, boiler load is the amount of heat transferred from the combustion to the steam cycle. These disturbances are selected to capture the CHP plant-DH system interaction; with scenarios for both the impact of CHP operation on the DH system, and the effect of DH network operation on the CHP plant performance. Boiler load level variability also allows the study of internal CHP plant dynamics, in relation to operational flexibility. The disturbances, or input variations, are simulated as theoretical step changes in an open loop setting, ramps and sinusoidal oscillations, as described in Sections 2.1-3. The simulation results are presented in Section 6 and 
discussed in Section 7. Focus is given to the plant's steam cycle with main emphasis on power and district heating generation.
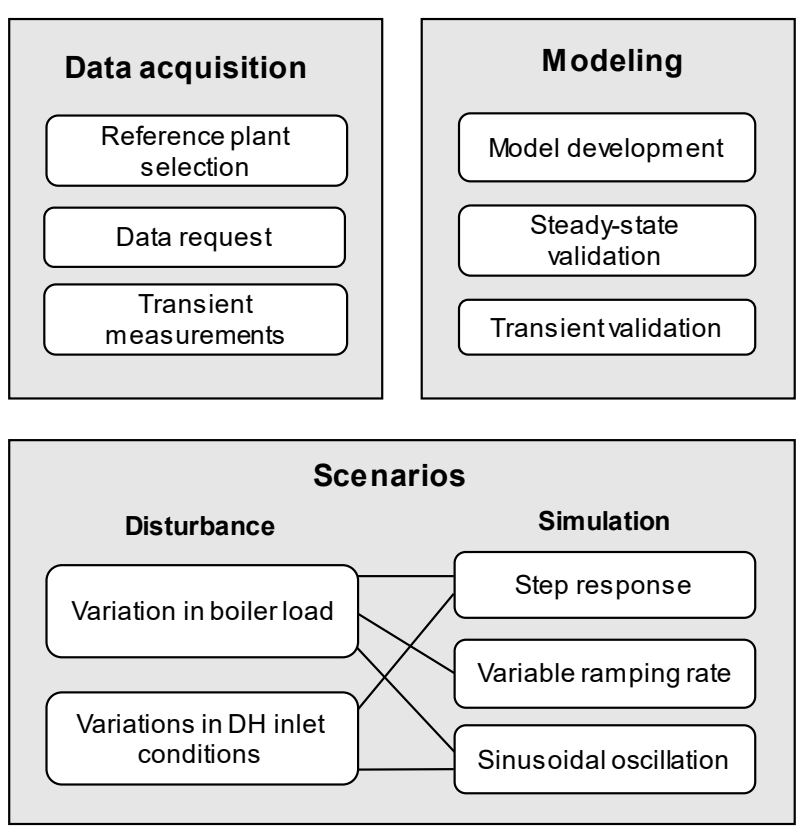

Figure 1. Methodological overview of reference data acquisition, model development and validation, and simulated scenarios simulations.

\subsection{Open loop step responses}

The step change simulations consider variations in boiler load and district heating mass flow rate and inlet temperature. The model is initialized to steady-state before each step, which has a duration of $1 \mathrm{~s}$ to avoid numerical problems associated with simulation of pure step changes. For the boiler load, six steps are performed in a series of increases and decreases between $100 \%$ and $70 \%$ of full load, changing the load level with $10 \%$ for each step, as principally illustrated in Figure 2a. For district heating, the disturbance variables are changed in steps of $\pm 10 \%$ of the corresponding steady-state value, Figure $2 \mathrm{~b}$. Two cases are compared, for $100 \%$ and $70 \%$ boiler load respectively, to study if the process dynamics differ between design and off-design operating conditions. The simulated time between two steps is $10000 \mathrm{~s}$. 


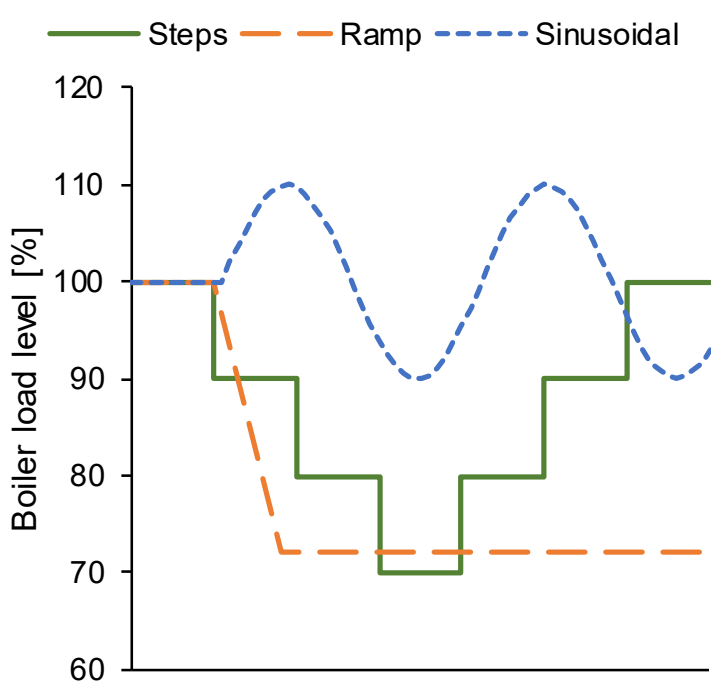

a) Time

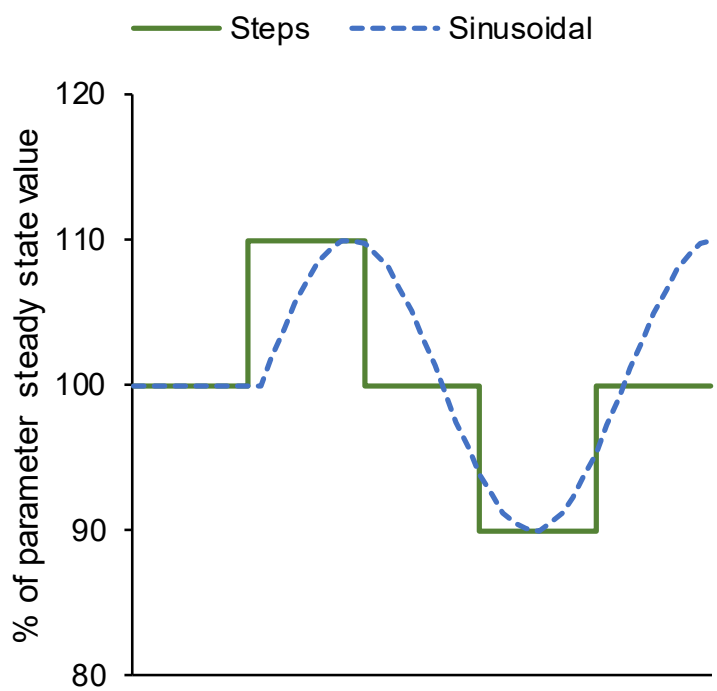

b) Time

Figure 2. Set-point changes related to step changes, ramps and sinusoidal oscillations in a) boiler load level, and b) district heating inlet flow and temperature. Each step change has a duration of 1 s although not seen in the figures. The ramp rate and oscillation frequency are varied.

The step responses of key process variables are analyzed in terms of settling time and relative change in process variable value, $R C$. The settling time is here taken as the $95 \%$ response time; that is, the time required for the process variable to reach and remain inside a band whose width equals $\pm 5 \%$ of the total change in the process variable [34]. The relative change is calculated with Equation 1.

$$
R C(\%)=100 \cdot \frac{y_{\infty}-y_{0}}{y_{0}}
$$

Four response variables are analyzed:

- Power generation $[\mathrm{MW}]$

- District heating production [MW]

- District heating outlet temperature $\left[{ }^{\circ} \mathrm{C}\right]$

- Live steam mass flow $[\mathrm{kg} / \mathrm{s}]$

\subsection{Variable ramping rate}

Boiler load changes at varying ramping rates $(2,4,8$ and $16 \%$ of full load/min) are simulated, by applying a boiler load reduction from 100 to $72 \%$ of full load, see Figure $2 \mathrm{a}$ for a principal example. $2 \% / \mathrm{min}$ is the reference plant design ramp rate. The model is initialized to steady-state before the ramp is introduced. The rise time of each response is calculated. Here, the rise time is defined as the time to go from $10 \%$ to $90 \%$ of the steady-state response [34].

In practice, waste is a heterogeneous fuel with considerable differences in heating value. Fluctuations around the design value on short timescales are handled by the boiler inertia and not noticed by the steam cycle, while variations in mean heating value over a longer time will be seen by the steam cycle as a load change. These effects are not the focus of the present investigation and ramp rates are given as a constant rate of change in boiler load and gas flow. This assumption is made to simplify the modeling and to isolate the impact of ramp rate on the dynamic steam cycle responses.

\subsection{Sinusoidal oscillations}

Simulations of how the steam cycle responds to sinusoidal changes in the input variables are performed, for the same disturbances as in Section 2.1. A similar study was conducted in [35] for a gas turbine combined cycle plant, which, however, was operated as a condensing plant and not in a CHP scheme. Figure 2a and b show examples 
of the input oscillations. In this work, the amplitude of the sinusoidal input was set to $10 \%$ of the steady-state value of the DH flow or temperature, or $10 \%$ of boiler full load; while the frequency of oscillation was varied (10, $100,300,1000$ and $3600 \mathrm{~s}$ ). These variations in frequency were chosen to identify the characteristic timescale of the process; that is, what frequency of disturbance is required to cause the response variable to deviate significantly from its steady-state condition. The deviation from steady-state is measured as the amplitude of the periodic response variable, compared to the absolute change that would result from the corresponding step change; yielding a relative amplitude of oscillation, $R A$ :

$$
R A=\frac{A}{A_{\infty}}
$$

\section{Combined heat and power plant configuration}

The dynamic steam cycle model is based on a municipal solid waste-fired CHP plant installation at Mälarenergi, Västerås, Sweden, with plant details given in Table 1 and a process diagram of the plant in Figure 3 . The plant consists of a circulating fluidized bed (CFB) boiler, a steam drum, a flue gas back pass, a flue gas cleaning system, a steam turbine, two district heating condensers, a feed water preheating system, and a control system structure. Although the steam turbine is intended to always be in operation, there is also a turbine-bypass condenser installed at the plant (not included in Figure 3 or in the model) to allow the plant to operate as a heat only boiler.

In this work, the main part of modeling interest is the subcritical steam cycle and the interconnection to the district heating network, leaving the combustion and gas side outside the scope. From a plant operation perspective, the description of the combustion and emission control system during changes in load or fuel composition is important. However, from a steam cycle perspective, combustion is primarily a source of heat for steam generation that can be treated like a source term; thus, drawing a model boundary between the gas side and steam side is efficient in steam cycle modeling. See the following references for more on combustion of waste in grate-fired [32] and CFB [33] boilers. Thus, the model is based on a detailed representation of the steam cycle and the flue gas back pass; but coarsely describes the combustion and heat capacity of the CFB part of the boiler and neglects the flue gas cleaning system. The boiler and steam cycle are described in the following subsections.

Table 1. CHP reference plant design data

\begin{tabular}{ll}
\hline Boiler fuel capacity [MW] & 167 \\
Turbine rated capacity [MW] & 48 \\
DH design load [MW] & 110 \\
Power-to-heat ratio (appx.) [-] & 0.43 \\
Live steam temperature $\left[{ }^{\circ} \mathrm{C}\right]$ & 470 \\
Live steam pressure $[\mathrm{bar}]$ & 75 \\
Live steam design flow $[\mathrm{kg} / \mathrm{s}]$ & 55 \\
Drum pressure $[$ bar $]$ & 85 \\
Feed water temperature $\left[{ }^{\circ} \mathrm{C}\right]$ & 135 \\
\hline
\end{tabular}




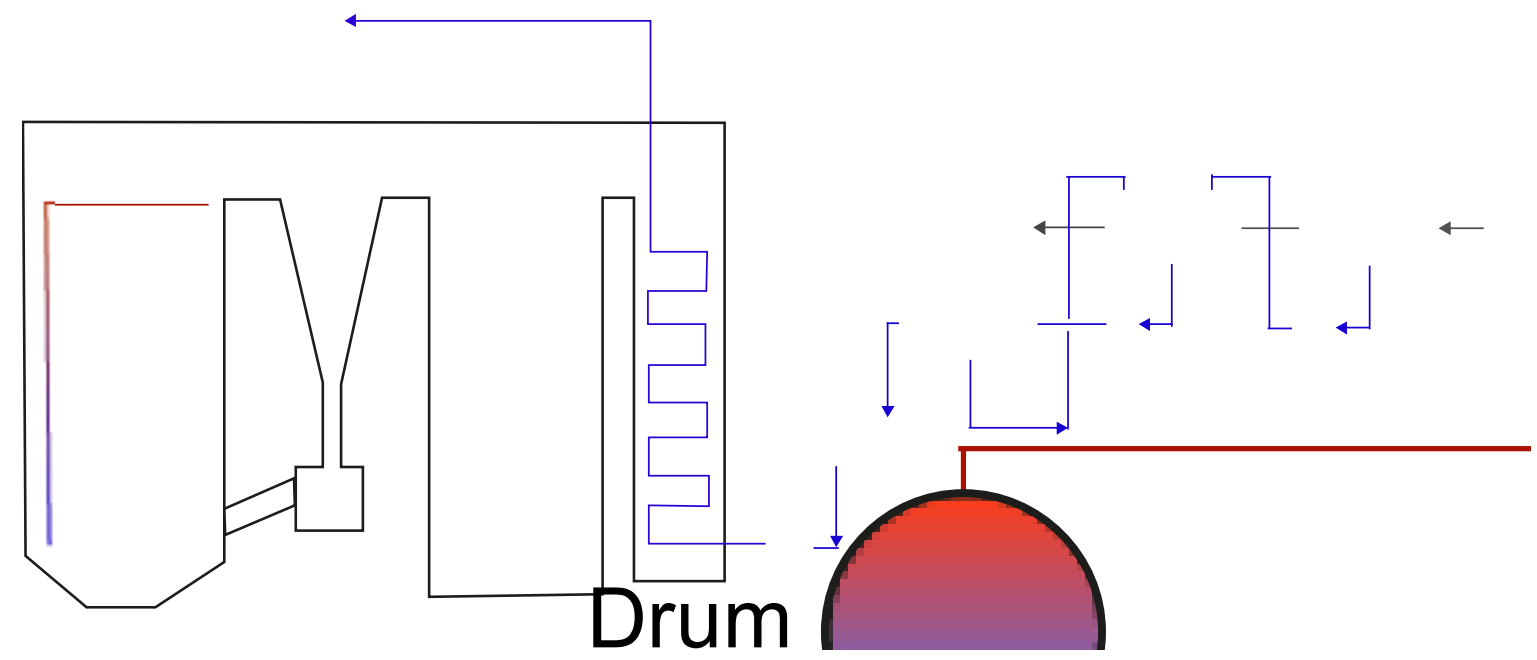

Figure 3. An overview of the CHP plant configuration, with CFB boiler, steam drum, flue gas back pass, steam turbine, district heating condensers and feed water system. Numbers refer to key process variables: 1. Power generation, 2. DH outlet conditions, 3. DH inlet conditions, 4. Live steam parameters. Nomenclature: BB-Boiler bank, SH - Superheater, ECO - Economizer, LPFWH - Low pressure feed water heater, DEA - Deaerator, COND - Condenser, HP - High pressure turbine, LP - Low pressure turbine, GEN - Generator, DH - District heating.

\subsection{Boiler and flue gas pass}

An overview of the boiler and flue gas pass is shown in Figure 3. The boiler includes an economizer (ECO) that preheats subcooled feed water; water walls (RISERS) where feed water is heated to the saturation temperature and partly evaporated; a natural circulation steam drum (DRUM) where steam and water are separated; and superheaters (SH 1-3) where saturated steam is heated above the saturation temperature. Three stages of superheaters are included, with intermediate spray attemperators (SPRAY 1-2 in Figure 4) for steam temperature control. The first two stages of superheating are placed in the flue gas back pass as tube bundles, while the third stage is located in the CFB loop-seal, being heated by the circulated hot bed material. Evaporating sections (RISERS) are located in the furnace, the cyclone, and in the flue gas back pass. The economizer is placed last in the flue gas train. The exiting flue gas progresses to the flue gas cleaning system before being vented through the stack (not shown). Figure 4 shows a simplified block diagram illustrating the flow paths of flue gas and water/steam that are applied in the CHP steam cycle model. Since the combustion and heat capacity of the CFB part of the plant is outside the scope of this work, the heat transfer from flue gas to water in the CFB; that is, the evaporating sections in the furnace and cyclone, and tertiary superheater; have been replaced by heat source boundaries in the model, indicated by yellow arrows in Figure 4. 


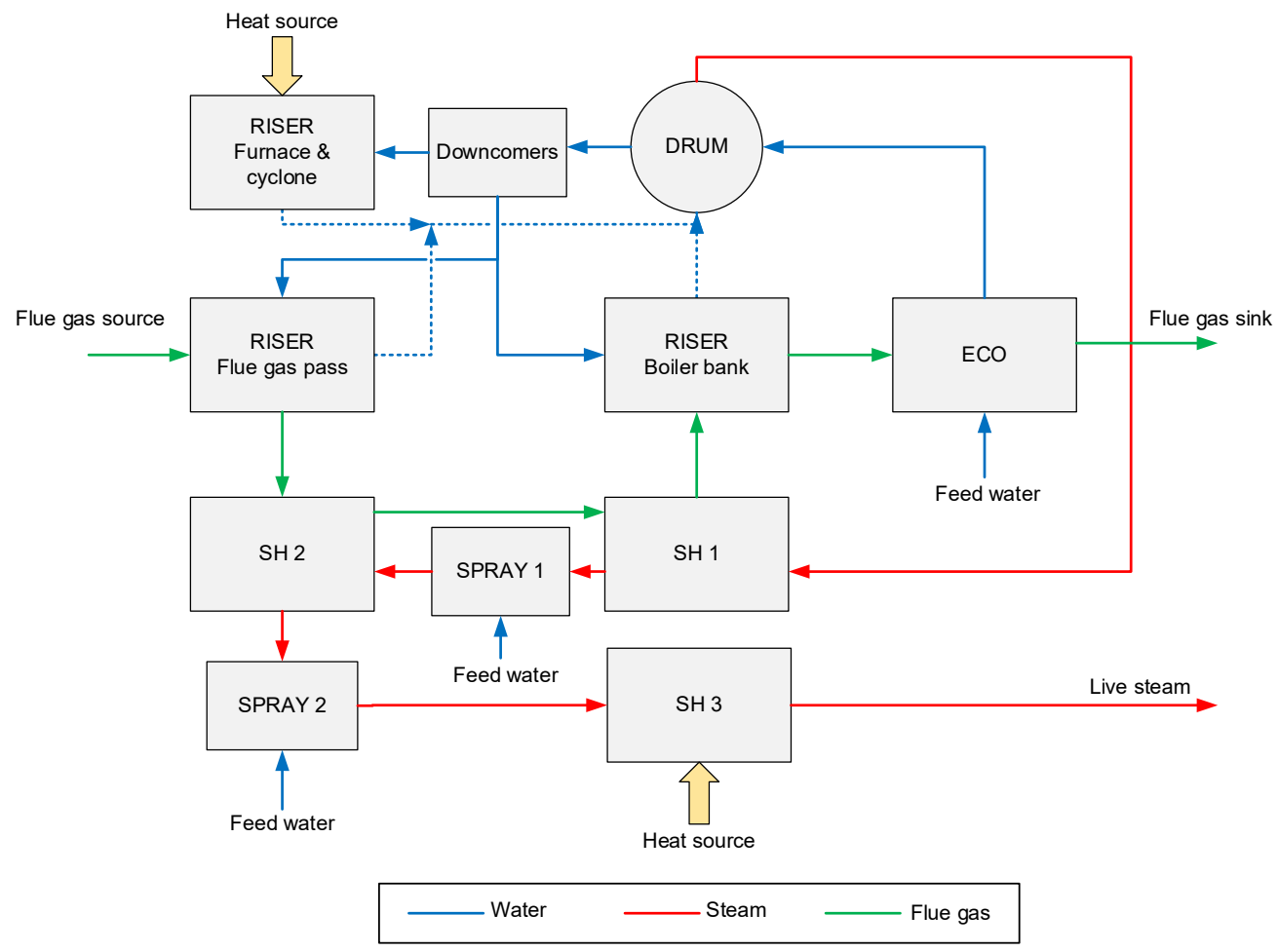

Figure 4. A simplified block diagram of the flue gas pass with the flow paths of water/steam and flue gas, as modeled in this work. Heat sources (yellow) are used to represent the heat transfer processes taking place in the CFB part of the boiler. Modified from [18].

\subsection{Turbine, district heating and feed water regeneration}

The steam side consists of a steam turbine (HP and LP sections), a generator (GEN), two district heating condensers (COND 1-2), a low-pressure feed water heater (LPFWH), a deaerator tank (DEA) and feed water and condensate pumps (PUMP 1-3). The configuration is visualized in Figure 5. Live steam from the boiler is expanded in the steam turbine, resulting in electricity production. The turbine is constructed in two sections with steam extractions at three pressure levels. Connected to the turbine are one backpressure and one extraction condenser, where district heating water is heated by condensing steam from the turbine outlet and the low-pressure extraction. The intermediate-pressure steam extraction is used for feed water preheating in the LPFWH. The condensate from the backpressure condenser and the LPFWH is collected in the extraction condenser before the total amount of condensate is preheated and delivered to the deaerator that also acts as a feed water storage tank. The deaerator receives steam from the high-pressure extraction. The feed water pump closes the steam cycle and returns feed water to the boiler. 

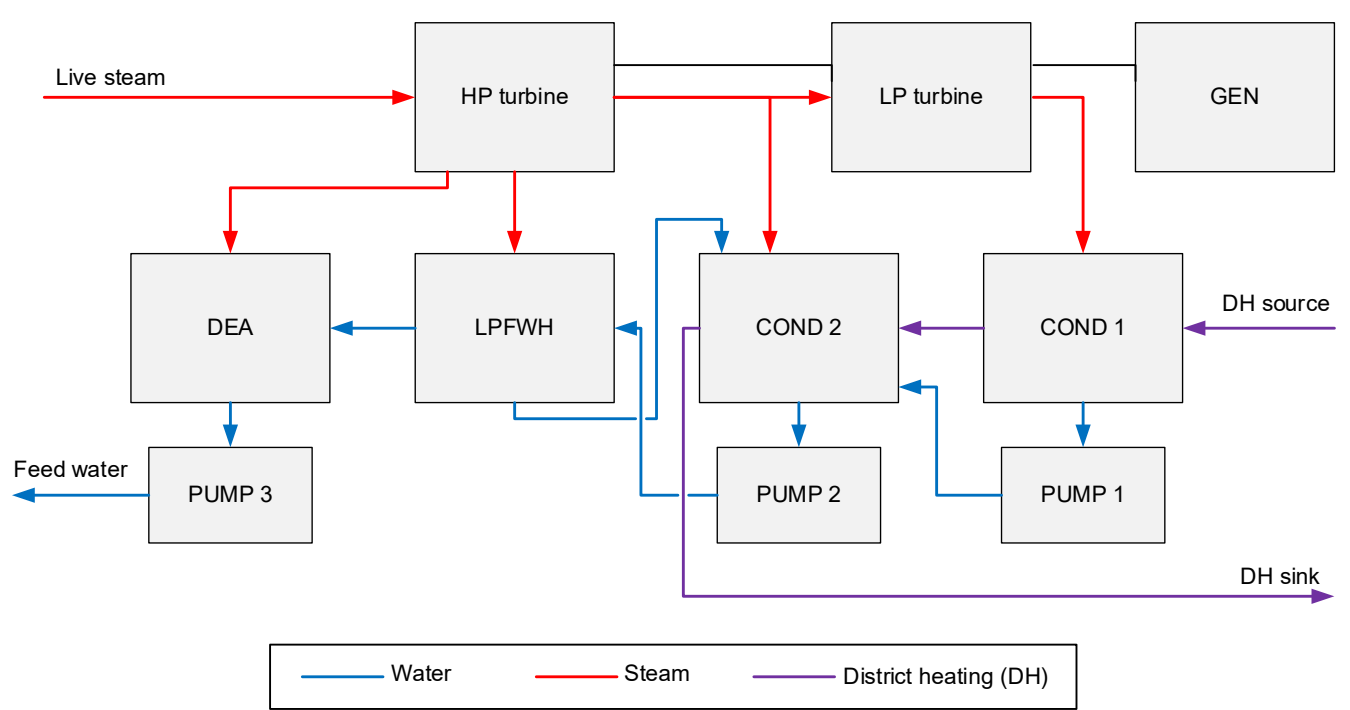

Figure 5. A simplified block diagram of the turbine, district heating and feed water system, representative of the reference plant. Modified from [18].

\section{Model description}

The dynamic CHP plant model is constructed in the commercial software Dymola [36], which is based on the modeling language Modelica [37], using the component library ThermalPower from Modelon [38], which has been used to model power plants in a number of previous studies [18,19,22,24-26]. The components are modeled based on differential and/or algebraic mass and energy balance equations. The following subsections describe the modeling of the plant components in detail.

\subsection{Flue gas pass - Gas-two-phase heat exchangers}

The flue gas pass is modeled as a series of shell-and-tube heat exchangers, as illustrated in Figure 6 . The component consists of two pipe flow models for the gas and steam/water sides respectively, that are connected through a wall model that transfers heat between the pipes. The geometries of the pipe channels are parameterized according to detailed equipment design specifications of the reference boiler; including pipe dimensions, number of passes, and tube pitch.

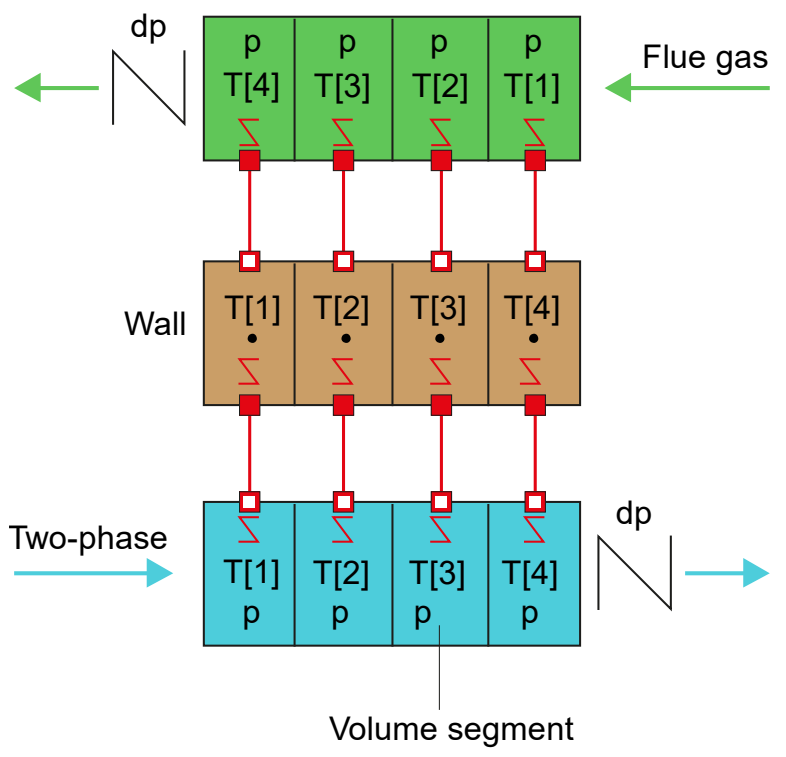

Figure 6. General layout for the gas-two phase heat exchanger model used in this work. The pipes and wall are discretized in 4 volume segments, each connected to a heat port. Heat transfer resistances are included. Pipe pressure drops are lumped at the outlets. Modified from [38]. 
The gas side pipe is described by static mass and energy balances (Equations 3-4), as the gas volume dynamics are assumed to be rapid with design flue gas velocities of $4-7 \mathrm{~m} / \mathrm{s}$, resulting in approximate residence times of 2$8 \mathrm{~s}$ depending on the component size. Flue gas time constants of heat recovery steam generator heat exchangers, which can be considered similar to the flue gas pass modeled here, have previously been identified as at least one order of magnitude faster than the water-side heat exchange [39], motivating a quasi-static assumption for the gasside. However, separate gas volumes are included between heat exchanger models to account for gas side residence times. Similar assumptions were used in [24]. The flue gas composition is assumed based on complete combustion of the fuel. The pipe is discretized into 3 - 6 volumes depending on the boiler component [40].

$$
\begin{aligned}
& \frac{d \dot{m}}{d t}=0 \\
& \dot{m}\left(h_{\text {out }}-h_{\text {in }}\right)=\alpha A\left(T_{\text {gas }}-T_{\text {wall }}\right)
\end{aligned}
$$

The convective heat transfer coefficient, $\alpha$, is calculated from a correlation for 1-phase gas side heat transfer over tube bundles using Equation 5. The coefficient is calculated for each pipe segment with a Nusselt correlation covering both laminar and turbulent flow regions. $\mathrm{C}$ is a calibration factor that is used, when appropriate, to fine tune the heat transfer with the reference power plant data, by enhancement or reduction of the heat transfer coefficient. The Nusselt number, Nu0, is calculated from Reynolds number dependent correlations from VDIWärmeatlas [41].

$$
\alpha=C \frac{F_{a} * N u_{0} * \lambda}{d_{h y d}}
$$

The correlation above is used in all heat exchanger gas phase pipes with one exception - the vertical evaporator tubes in the first part of the flue gas pass, where the correlation below has been fitted to the heat exchanger model. The parameter $K$ is an empirical coefficient that is fitted to the model based on steady-state process data for three boiler load levels (72, 87 and $100 \%$ of full load). The correlation has previously been used to model similar gas side heat transfer to evaporator tubes in CFB boilers [42] and coal-fired furnaces [43].

$$
\alpha_{e m p}=K \dot{m}_{g}{ }^{0.6}
$$

The water side pipe model is similar to the gas side pipe but includes a dynamic mass balance instead of a static one.

$$
\frac{d \dot{m}}{d t}=\dot{m}_{\text {in }}-\dot{m}_{\text {out }}
$$

The water side heat transfer correlation is chosen based on the number of phases present; with one correlation for 1-phase flow (in economizer and superheaters), and one for 2-phase flow (in evaporator sections). The singlephase correlation is, similar to the gas side, geometry based and modeled with a Nusselt correlation, see Equation 5. However, the tube arrangement factor, $F_{a}$, is excluded. For two-phase flow a correlation for convective evaporation in vertical tubes is applied, based on Equations 8-12 as:

$$
\begin{aligned}
& \alpha_{t p}=\psi \alpha_{L} \\
& \alpha_{L}=0.023 R e^{0.8} \operatorname{Pr}_{L}^{0.4}\left(\frac{\lambda_{L}}{d_{\text {hyd }}}\right) \\
& \psi=f(C o, B o) \\
& \text { Co }=\left[\frac{1-x}{x}\right]^{0.8}\left[\frac{\rho_{v}}{\rho_{L}}\right]^{0.5} \\
& \text { Bo }=\frac{q}{G h_{\text {vap }}}
\end{aligned}
$$


where the correlation in Eq (9) is a modification of the Dittus-Boelter equation, where the liquid heat transfer coefficient is multiplied with an enhancement factor calculated based on the steam quality (Co number) and the Boiling number, Bo. A similar correlation was used in [44].

The pipe pressure drops, $d p$, are calculated with a friction loss correlation, and are lumped at the pipe outlets, assuming a uniform pressure in all nodes as illustrated in Figure 6. A friction loss coefficient, $K_{f}$, is calculated based on the nominal operating point, assuming turbulent flow [45] (Eq 13).

$$
\begin{aligned}
d p & =\frac{K_{f} \dot{m}^{2}}{\rho} \\
K_{f} & =\frac{d p_{\text {nom }} * L F * \rho_{\text {nom }}}{\left(\frac{\dot{m}_{\text {nom }}}{n_{\text {channels }}}\right)^{2}}
\end{aligned}
$$

The wall connecting the pipes is modeled as being flat and 1-dimensional, and has a thermal resistance, $R_{w}$. The wall heat capacity is lumped at the center of wall, see Figure 6, and the wall heat accumulation is given by Equation 16. The wall is discretized equidistantly in the longitudinal direction.

$$
\begin{aligned}
& R_{\text {wall }}=\frac{s / \lambda}{A} \\
& \frac{m_{\text {wall }} c_{p} d T}{d t}=\frac{2}{R_{\text {wall }}}\left(T_{\text {wall }, g}-T_{\text {wall }, S}\right)
\end{aligned}
$$

\section{Steam attemperators}

The steam attemperators located between the superheater steps are modeled as ideal mixing volumes, where feed water is sprayed into the steam. The mass flow of feed water to the attemperator is controlled, as described in Section 4.4. Dynamic mass and energy balances are used to describe the fluid side.

\subsection{Steam drum}

The steam drum is modeled as a cylindrical, horizontal drum, based on dynamic mass and energy balance equations of the liquid and vapor volumes in the drum. Dynamic modeling of steam drums has been studied and described by Åström and Bell [46] and Eborn [47]. Mass and energy transfer between the liquid and vapor phases is accounted for by bulk condensation of the vapor phase, and bulk boiling of the liquid phase. Accumulation of heat in the wall, and heat transfer through the drum wall is neglected.

\section{Risers}

Risers are modeled as discretized vertical water pipes, similar to the description in Section 4.1. Only the water side is considered. Heat is provided to the pipe from a source term, representing heat transfer from the furnace and cyclone. The two-phase heat transfer correlation described above is used to quantify the water side heat transfer. Natural circulation is achieved in the model by including ideal height difference components with pressure head.

\subsection{Turbine, district heating and feed water regeneration}

\section{Turbine}

The steam turbine is modeled in steps with intermediate extraction points. Stodola's law (Eq 17) is applied for determination of the turbine's off-design performance characteristics [48]; based on design conditions, the flow area coefficient, $K_{t}$, gives the effective turbine flow area of each step. Dry isentropic efficiencies (0.88-0.89 [49]) are specified for each turbine step and assumed to be constant for all loads. A Baumann coefficient, $\beta$, of 0.8 is used in the last low-pressure step to account for dry isentropic efficiency degradation due to steam condensation (Eq 18) [50]. The turbine is modeled as quasi-static with no consideration for the thermodynamic properties of the shaft, nor the thermal mass and inertia of the turbine. Only the thermodynamic differences of the inlet and 
outlet steam conditions are included (Eq 19). For the timescales considered in this work, a quasi-static assumption is justified by the relatively low turbine inertia compared to, for example, the boiler and turbine condensers [51]. A generator model is connected to the turbine shaft, with a mechanical efficiency of 99\% (Eq 20).

$$
\begin{aligned}
& K_{t}=\dot{m} \sqrt{\frac{R T}{p_{1}^{2}-p_{2}^{2}}} \\
& \eta_{\text {is,wet }}=\eta_{\text {is,dry }}-\beta(1-x) \\
& h_{\text {out }}=h_{\text {in }}-\eta_{\text {is }}\left(h_{\text {in }}-h_{\text {is }}\right) \\
& P_{\text {step }}=\eta_{\text {mech }} \dot{m}\left(h_{\text {in }}-h_{\text {out }}\right)
\end{aligned}
$$

\section{Condensers}

The two district heating condensers receive steam from the turbine outlet and the low-pressure extraction respectively. The condensers are modeled as horizontal, cylindrical vessels containing tubes for the cooling water. A hotwell is included below the cylinder bottom, that is sized based on an assumed residence time of 1 min under design conditions [52]. Dynamic mass and energy balances are used for the steam side, Eq 21-22, while the cold side is modeled with a static mass balance and neglects pressure losses, Eq 23-24. For the steam condensation, the model assumes thermodynamic equilibrium between the liquid and vapor phase, with no sub-cooling of the condensate. The liquid level, $y$, in the condenser is monitored (Eq 25) and asserts are triggered if the cylinder volume is full, stopping the simulation. It is assumed that there is no reduction in heat transfer area if the liquid level rises above the cooling tubes. A wall model (Section 4.1) connects the hot and the cold side.

$$
\begin{aligned}
& \frac{d \dot{m}}{d t}=\dot{m}_{\text {in }, s}-\dot{m}_{\text {out }, c} \\
& \frac{d E}{d t}=\dot{m}_{\text {in }, s} h_{\text {in }, s}-\dot{m}_{\text {out }, c} h_{\text {out }, c}-\dot{Q}_{\text {cool }} \\
& \dot{m}_{\text {in }}=\dot{m}_{\text {out }} \\
& p_{\text {in }}=p_{\text {out }} \\
& y=\frac{V_{l}}{A_{\text {surf }}}
\end{aligned}
$$

Heat transfer correlations are used on both tube sides. For the steam side, a geometry-based correlation for film condensation over horizontal tube bundles is used, taken from VDI-Wärmeatlas [53]. For the district heating water, a cooling liquid correlation is applied, using a logarithmic average of the inlet and outlet temperature as the driving temperature, Eq 26. The correlation is similar to the 1-phase water side correlation used in the boiler heat exchangers, but specially adapted for the liquid phase.

$$
\Delta T_{L M}=\frac{T_{\text {wall }}-T_{\text {in }}}{T_{\text {wall }}-T_{\text {out }}}
$$

\section{Feed water preheater}

The closed low-pressure feed water preheater receives steam from a turbine extraction that is condensed and subcooled. The component is modeled in a similar way as the condensers but includes an additional zone for condensate sub-cooling. The relative length of the sub-cooling zone is calibrated to 0.5 of the total length. The steam side is based on a drum model, where heat ports from the vapor and liquid phases are connected via a dynamic wall model to the cold side, which is modeled as a discretized, lumped pressure pipe, see Figure 7. Constant heat transfer coefficients are applied for the steam and condensate respectively. The single-phase heat transfer correlation described in Section 4.1 is used for the feedwater side. 


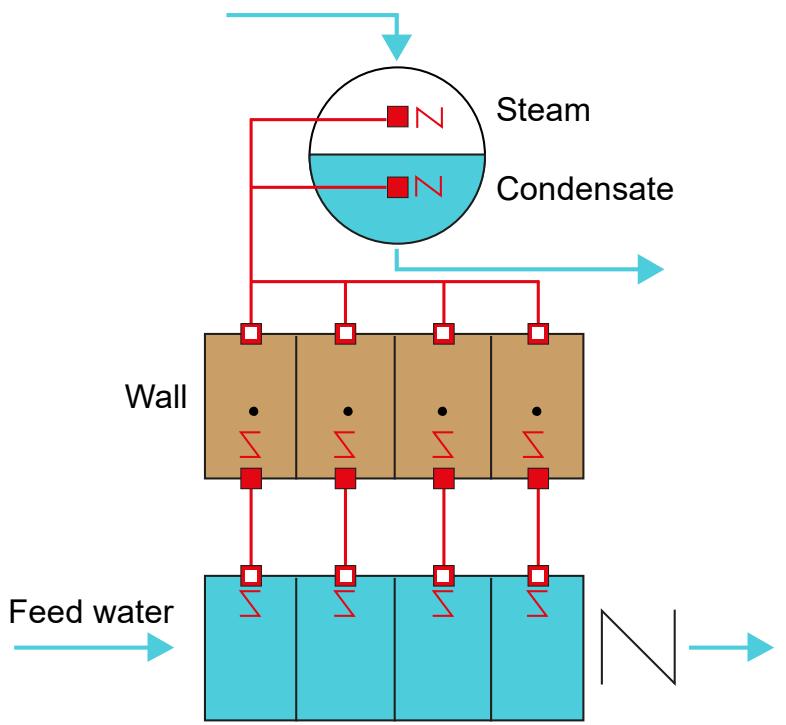

Figure 7. An illustration of the low-pressure feed water preheater model. A drum model is used to account for heat transfer from steam condensation and condensate sub-cooling. Modified from [38].

\section{Deaerator}

The deaerator is an open drum model, with assumed equilibrium between liquid and vapor phases. Heat transfer through the deaerator shell wall is neglected. Dynamic mass and energy balances are applied.

$$
\begin{aligned}
& \frac{d \dot{m}}{d t}=\dot{m}_{c}+\dot{m}_{s}-\dot{m}_{f w} \\
& \frac{d E}{d t}=\dot{m}_{c} h_{c}+\dot{m}_{s} h_{s}-\dot{m}_{f w} h_{f w}
\end{aligned}
$$

\section{Pump and valve configuration}

The condensate and feedwater pumps are modeled as centrifugal pumps based on quadratic flow characteristics, with constant rotational speed. The pump mechanical efficiency is set to $98 \%$, and isentropic efficiency to $80 \%$. Control valves are modeled as having linear valve opening flow characteristics, where the valve flow coefficient, $C_{v}$, in fully open condition is given implicitly by the nominal operating point, Eq 29-30. The flow is assumed to be turbulent [54], with static mass and energy balances.

$$
\begin{aligned}
& \dot{m}=\theta C_{v} \sqrt{\rho * d p_{\text {nom }}} \sqrt{\frac{p_{\text {in }}-p_{\text {out }}}{d p_{\text {nom }}}} \\
& C_{v}=\frac{\dot{m}_{\text {nom }}}{\sqrt{\rho * d p_{\text {nom }}}}
\end{aligned}
$$

\subsection{Regulatory control system structure}

The model includes a regulatory control layer that regulates the variables listed below. The control structure is based on common plant control practices [55], with support from design documentation and P\&IDs from the reference CHP plant. PID-controller tuning rules [56] are applied.

- PI level controllers are used to regulate the liquid content in the condensers and LPFWH, where the manipulated variable is valve opening. The deaerator level is allowed to fluctuate freely for inventory consistency [57].

- The steam drum level is controlled using a three-element PI-controller with input signals for drum level, feed water flow rate and steam flow rate.

- The live steam temperature is controlled by a cascade PI-controller structure where measurements of intermediate steam temperatures are used as inputs in the respective PI-controller. The set point live 
steam temperature is given externally. The manipulated variables are the spray attemperator valve openings.

- The live steam pressure and deaerator pressure are regulated with PI-controllers, that outputs the steam valve opening.

\subsection{Model boundary conditions}

Putting all the components described together, as illustrated in Figures 4 and 5, and implementing the control structure (Section 4.4), the complete model of the steam cycle of the reference plant is obtained, refer to Figure 3. The model uses input data from six boundary conditions, as specified below, to simulate the performance in the plant, for example the power produced and temperatures and flows at various points in the process. The six input boundary conditions to the power plant model are:

- Flue gas temperature at the inlet to the flue gas pass

- Flue gas mass flow

- Thermal load, furnace and cyclone

- Thermal load, tertiary superheater

- District heating mass flow

- District heating inlet temperature.

Flue gas and thermal load input values are used to control the boiler load. Input values for specific load levels are based on design specifications and process measurements during steady-state operation (100, 87 and $72 \%$ of boiler full load). Linear correlations are used to estimate boiler input parameter values for any load point within the interval $70-100 \%$ load, see Figure 8 . The correlations show a good fit to data, with $\mathrm{R}^{2}$-values above 0.99 . For the flue gas temperature, exact measurements of the temperature are used for steady state simulations. However, for transient analyses, the flue gas temperature is assumed to be constant due to small temperature variations at different load levels (3.4\% temperature difference), which do not correlate with load.

The district heating boundary values vary less predictably than the boiler input parameters but can be expected to remain within certain design limits. For instance, Gabrielaitiene et al. [58] simulated temperature variations and propagation of temperature waves in district heating networks; and Larsson [59] studied district heating system dynamics. For the purpose of simulations, representative values based on plant measurements are used. The mass flow varies with load, while the inlet temperature is kept between $50-55^{\circ} \mathrm{C}$.

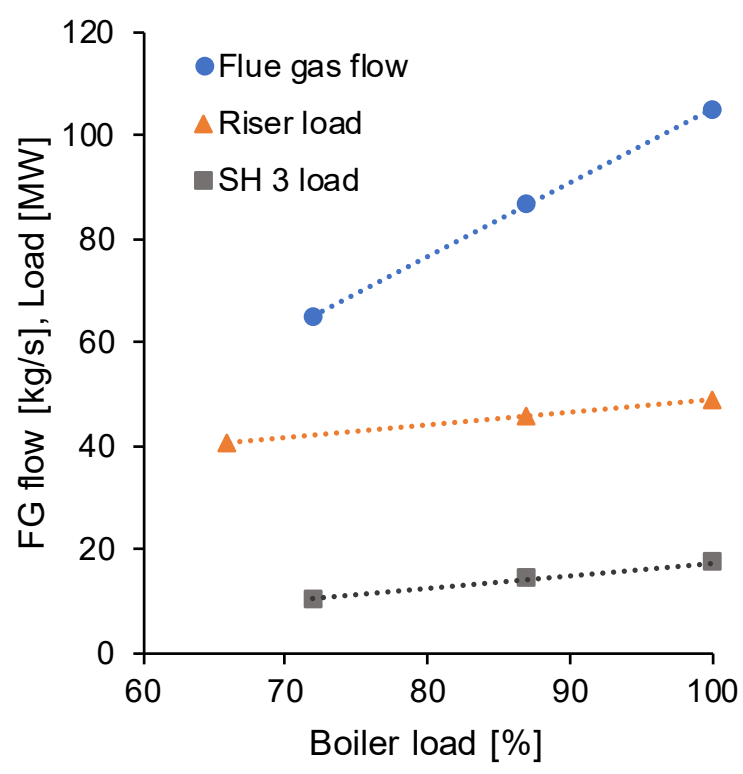

Figure 8. Correlations based on steady-state process data at varying boiler load levels are used as inputs to control the boiler load. 


\section{Model validation}

The CHP plant dynamic process model is validated with steady-state and transient measurement data from the reference plant for design and off-design conditions, following a similar method for dynamic process model validation with steady-state and transient plant data as presented in [60].

\subsection{Dynamic process model validation with steady-state plant data}

The dynamic model is validated against steady-state reference data from the plant at three load levels: $100 \%, 87 \%$ and $72 \%$ of full load. The dynamic model is simulated for each load level, with the corresponding reference data as input to the boundary conditions, until steady-state is reached. The steady-state simulation results for process variables are then compared with the respective reference value. The results are evaluated by calculating the absolute percentage deviations (AP) of the simulated value (SV) from the reference value (RV) for five key process variables, see Table 2 and Equation 31. All variable deviations are within 3\% from the reference. Given inherent measurement uncertainties and errors, the model shows good agreement with the reference plant data, indicating that the model captures the variability in terms of steady-state operating conditions for the full operational window of the plant, and demonstrates a proper implementation of the regulatory control layer that ensures stable operation of the plant process model.

$$
A P=100 \frac{|R V-S V|}{R V}
$$

Table 2. Steady-state validation results with percentage deviation from reference values of five process variables at three boiler load levels.

\begin{tabular}{lccr} 
Variable & \multicolumn{3}{c}{ Percentage deviation (\%) } \\
\hline Boiler load level (\% of full load) & 100 & 87 & 72 \\
\hline Power production & 1.18 & 2.60 & 0.45 \\
District heating generation & 0.33 & 1.29 & 2.51 \\
Live steam mass flow & 1.08 & 1.91 & 0.74 \\
Turbine inlet steam pressure & 0.50 & 0.07 & 2.69 \\
DH outlet T & 0.14 & 0.62 & 1.02 \\
\hline
\end{tabular}

\subsection{Transient validation of dynamic process model}

The transient validation compares simulation results to plant measurement data for three hours of operation, during which seven step changes in boiler load were performed. The step changes were performed as $10 \%$ increases or decreases of the boiler load level ( $\%$ of full load), within an operational load range of 70-100\%. The boiler load level step changes are visualized in Figure 9. 


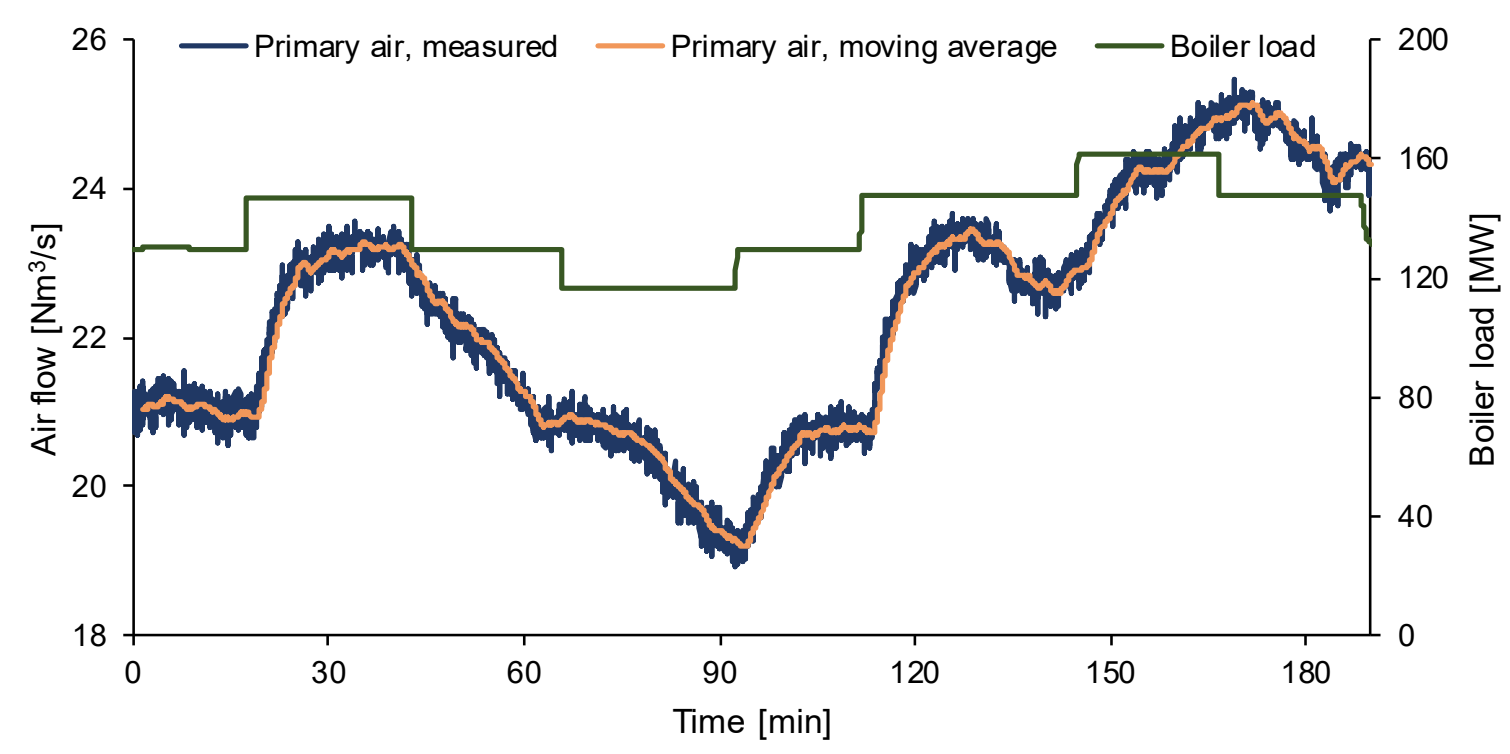

Figure 9. Boiler load step changes performed during transient measurements, as well as primary air flow after filtering with a moving average, compared to measurements. $100 \%$ boiler load corresponds to around $167 \mathrm{MW}$. Each step represents a 10\% change in boiler load.

As mentioned in Section 4.5, the boiler load is in the model characterized by input values for flue gas flow and temperature, and thermal loads for risers and the tertiary superheater. Thus, to simulate the step changes in boiler load, transient input profiles based on the plant measurements are provided to the model boundary conditions, as plotted in Figure 10. The inputs for district heating mass flow and temperature are measured values, while the other inputs are based on processing of the measurements. The flue gas flow profile is correlated to measurements of primary air flow, based on design and process data. Thermal load inputs at the furnace and cyclone (Riser load) and tertiary superheater ( $\mathrm{SH} 3$ load) boundaries are correlated with the measured boiler load change according to Figure 8. Measurement noise is reduced using a moving average filter, see for example Figure 9 where primary air flow measurements are compared to the moving average filtered values.

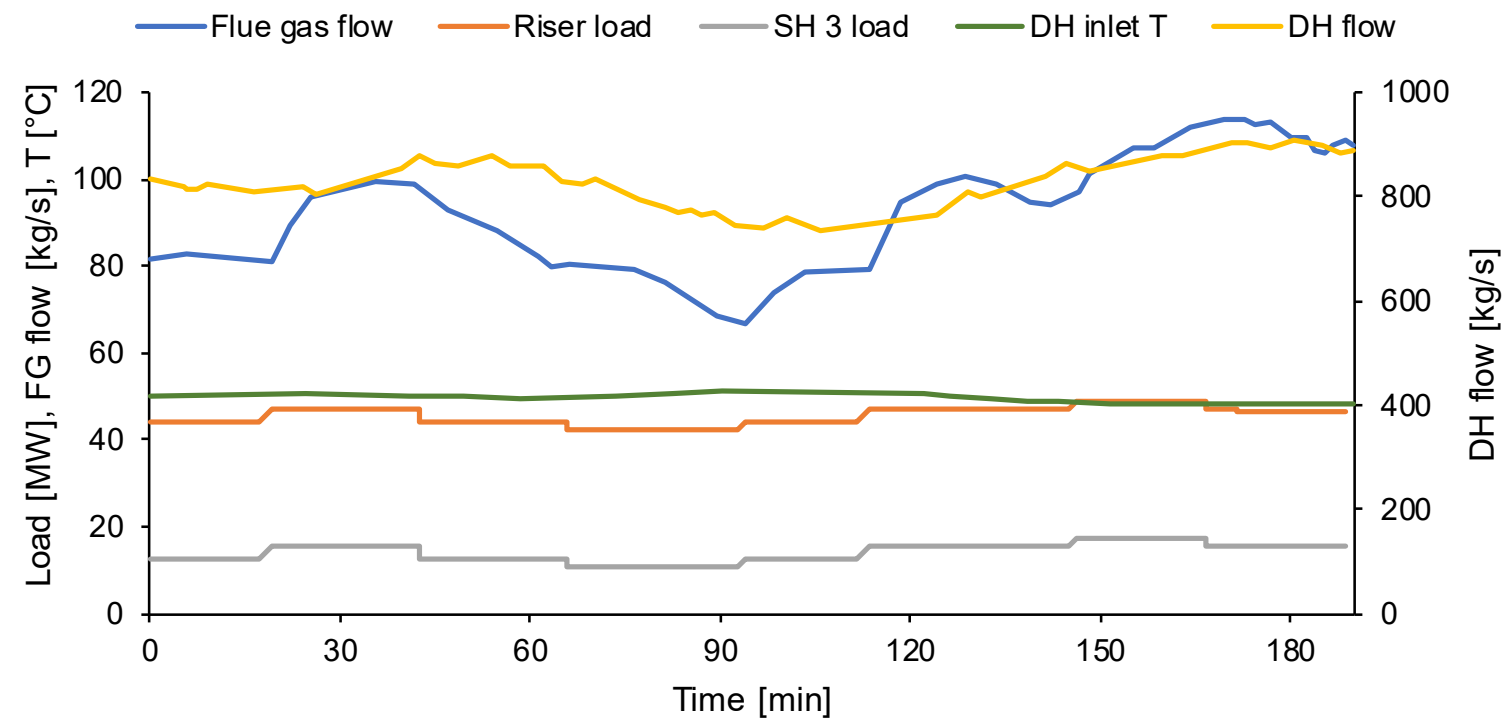

Figure 10. Input profiles to the model boundary conditions for the transient model validation simulation.

The resulting output from the simulation is compared to plant measurement data, for four process variables: power generation (Figure 11a), live steam mass flow (Figure 11b), district heating generation (Figure 11c), and district 
heating outlet temperature (Figure 11d), see points 1-4 in Figure 3. The plotted simulation results have been vertically shifted to match the measurements and better visualize the trends. The motivation for this is that having a precise model with only small deviations from the reference values is not the main priority of this study, and steady-state deviations of the main process variables are reported in Table 2. Higher importance is given to the demonstration of accurate trends associated with the dynamic process changes. Figures 11a-d show that, in general, the simulation results follow the reference measurement data well, in terms of time; with some slight discrepancies in variable value, mainly for district heating outlet temperature (Figure 11d). The model is, thus, considered to capture the trends and transient characteristics of the CHP plant in an adequate way for the purpose of this study.

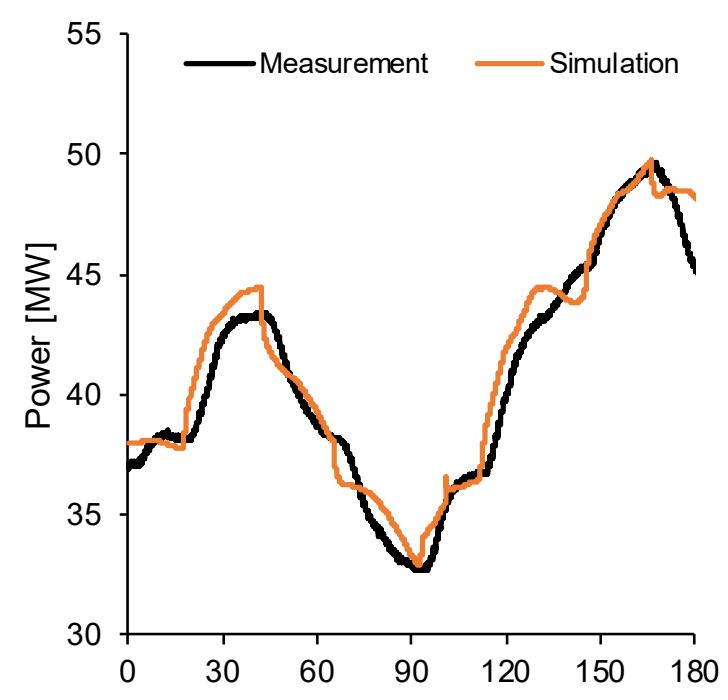

a) Time [min]

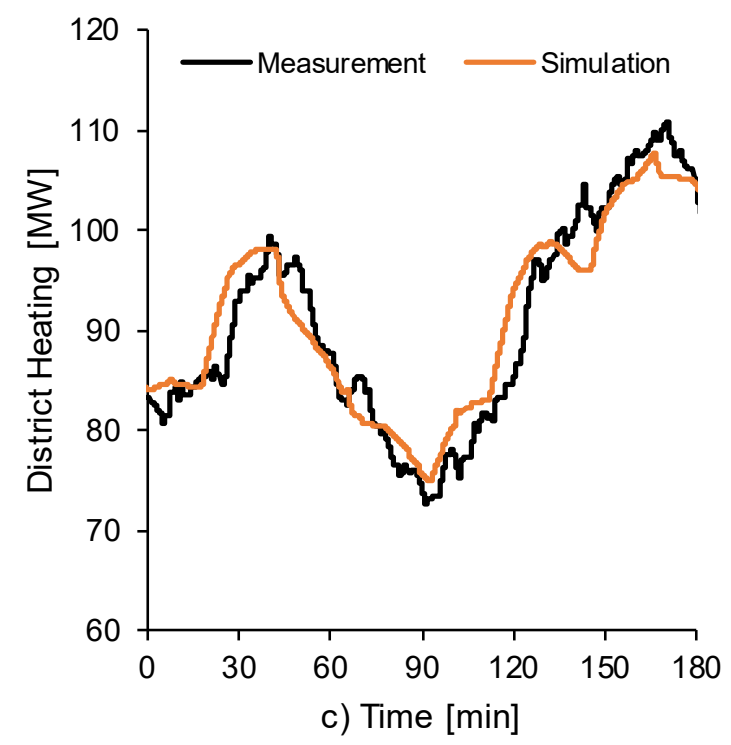

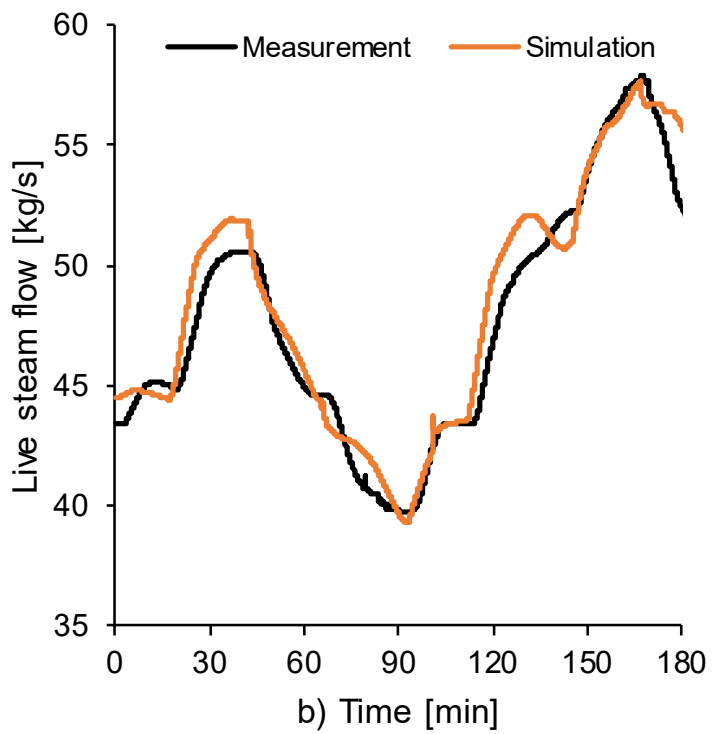

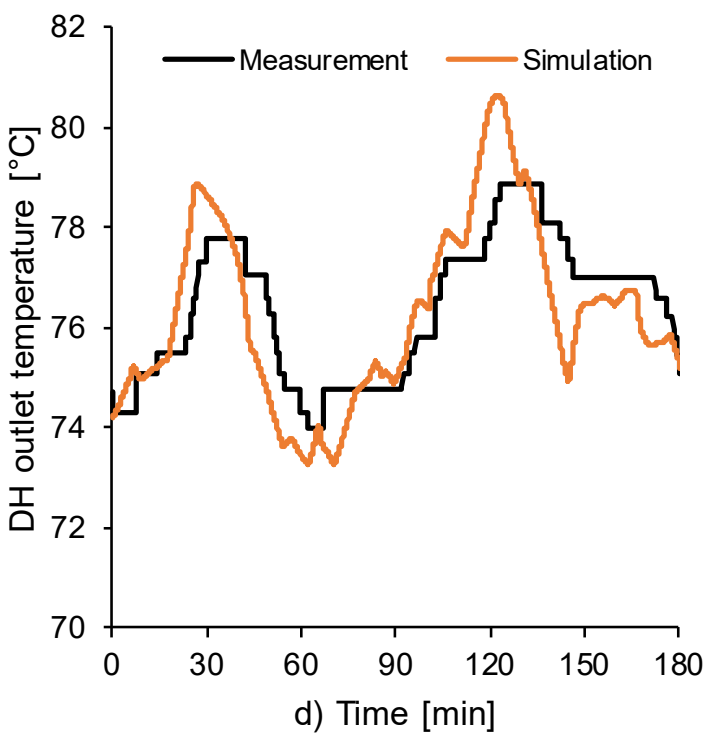

Figure 11. Transient validation results with simulated values compared to measurements: a) power generation, b) live steam mass flow, c) district heating generation, d) district heating outlet temperature.

\section{Simulation results}

This section presents simulation results of the scenarios studied to characterize the waste-fired CHP steam cycle dynamics: i.e. how key power plant process variables respond to operational changes when theoretical step 
changes, ramps and sinusoidal oscillations in boiler load and DH mass flow and temperature are applied as disturbances to the steam cycle model.

\subsection{Step responses to boiler load changes}

Figure 12 shows the settling times in minutes of the four response variables for the six boiler load step changes. In terms of settling time, it takes longer for the process variables to reach the new steady state value at part load compared to full load; the difference is $2-5$ minutes depending on the variable. Furthermore, the settling times tend to be longer for step decreases in boiler load than for increases. However, all settling times are within 15 minutes for the response variables. The relative changes associated with the step changes in boiler load level are: $10-14 \%$ for power generation, $\mathrm{DH}$ production and live steam flow; and around $4 \%$ for $\mathrm{DH}$ outlet temperature.

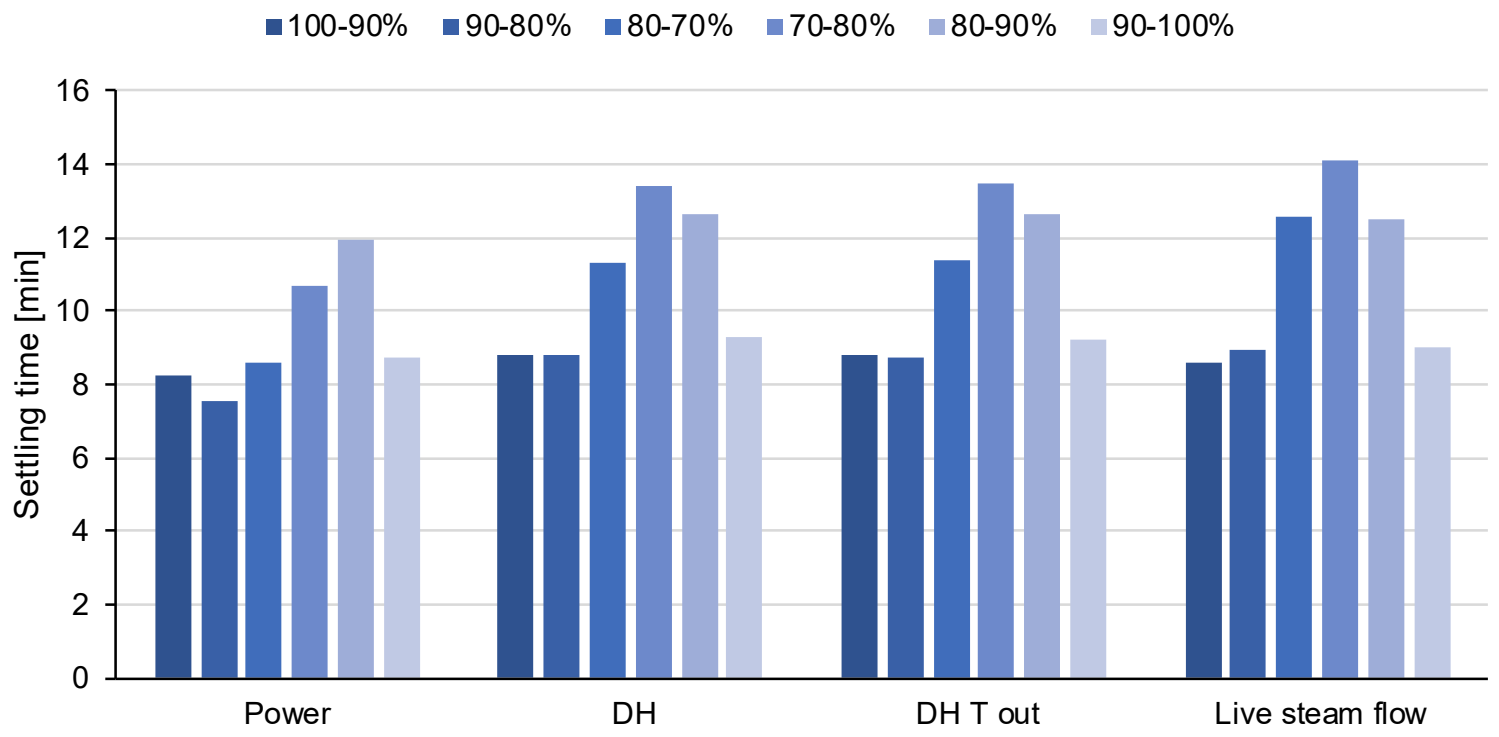

Figure 12. Settling times for response variables for step changes in boiler load.

\subsection{Step responses to district heating inlet disturbances}

The settling times for power output, DH generation and DH outlet temperature for step changes in DH mass flow and inlet temperature, are presented in Figure 13. Green bars represent changes in DH flow, while yellow is used for DH inlet temperature. The left side of the figure shows responses for operation at boiler full load, and the rightside shows part load responses. Similar to the boiler load step changes in Section 6.1, the settling times for district heating input disturbances are consistently longer at part load than full load operation, illustrated with the dashed line in Figure 13. However, there is no clear tendency to which type of disturbance yields the fastest settling times. Most process variables settle at the new steady state value within 3 minutes, with power output being the fastest response variable with settling times of 1-2 minutes. Live steam parameters are not affected by these step changes; instead the observed change in power output is caused by variations in the required extraction pressure in, especially, the extraction condenser; which is affected by the temperature of the district heating water. 


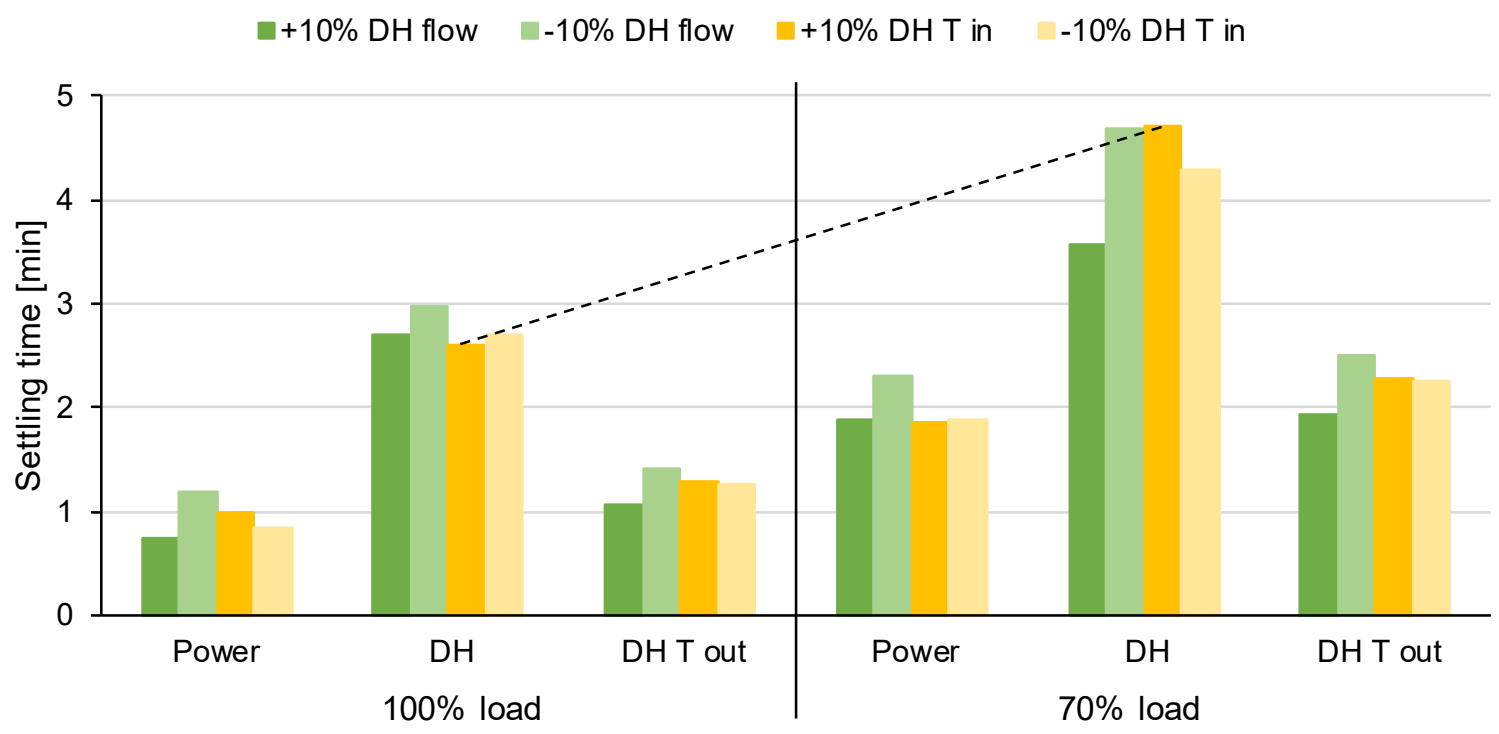

Figure 13. Settling times for response variables for step changes in district heating inlet disturbances $( \pm 10 \%$ changes in district heating flow or inlet temperature) at two boiler load levels (100\% and $70 \%$ of full load). The dashed line exemplifies the increase in settling time at part load boiler operation, compared to full load.

The relative change in process variable outputs for step changes of district heating input variables are shown in Figure 14. The relative changes are slightly increased at part load, but this might be a function of lower offset value. In fact, the absolute changes (not presented here) do not differ significantly depending on load level. However, disturbances caused by changes in district heating inlet temperature tend to cause greater relative changes in the response variables than flow disturbances, for the $10 \%$ deviations considered here. In addition, decreases in flow, and to some extent increases in inlet temperature, also cause greater relative changes.

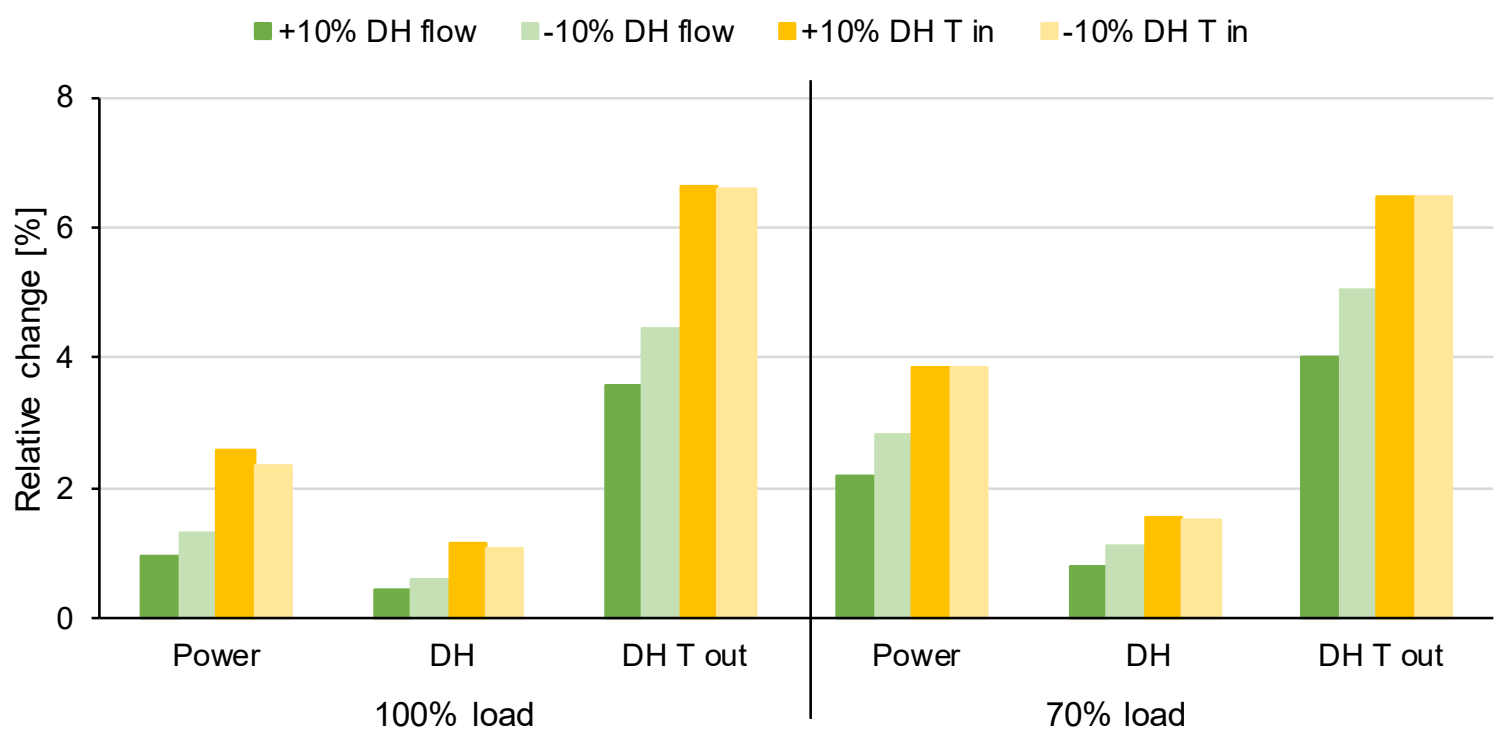

Figure 14. Relative changes in response variables for step changes in district heating inlet disturbances $( \pm 10 \%$ changes in district heating flow or inlet temperature) at two boiler load levels (100\% and $70 \%$ of full load).

\subsection{Variable ramping rate}

The variable ramp rate simulations are analyzed for one response variable, power generation. Figure 15a shows the rise times (time to go from $10 \%$ to $90 \%$ of the steady-state response) associated with the obtained ramp 
responses plotted in Figure 15b. The rise times are between 4-12 minutes for a boiler load reduction of $100 \%$ to $72 \%$ of full load. When the ramp rate is doubled from 2 to $4 \% / \mathrm{min}$, the rise time is nearly halved ( $42 \%$ reduction). However, further doubling of the ramp rate indicates diminishing rise time reductions. Compared to the step change (rise time of 3.9 minutes), the $4 \% / \mathrm{min}$ and the $8 \% / \mathrm{min}$ are only 2.9 and 1.1 minutes slower to reach $90 \%$ of the steady-state value, respectively.

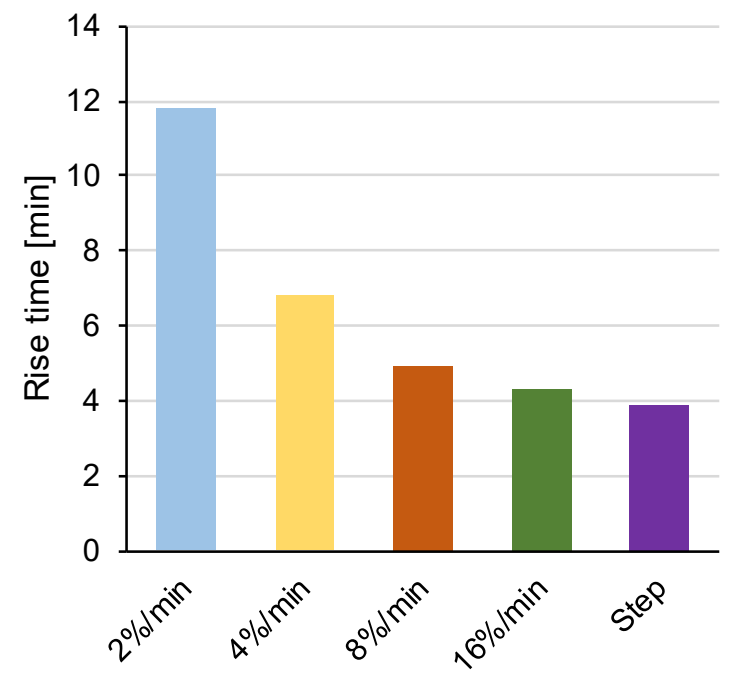

a) Ramp rate

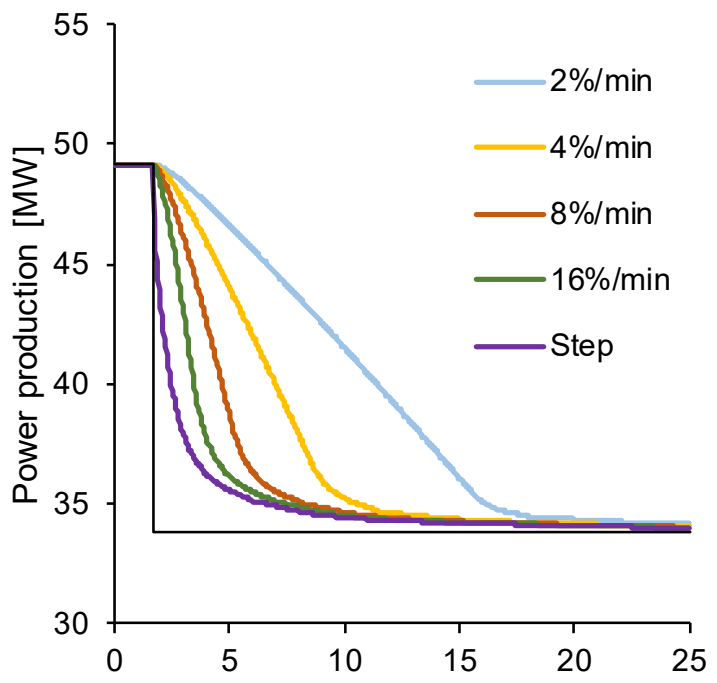

b) Time [min]

Figure 15. Results from variable ramp rate simulations of a boiler load reduction from 100\% to $72 \%$ of full load. Results are displayed for the process variable power production: a) the rise times associated with the ramp rates, and $b$ ) the observed responses, where the ramp is introduced at time $=1.67 \mathrm{~min}$.

\subsection{Sinusoidal oscillations}

Figure 16 shows the responses of the power generated for boiler load oscillations with varying period times. Clearly, the frequency of oscillation impacts the magnitude of the response observed, with higher frequency (shorter period time) yielding smaller deviations from the offset value.

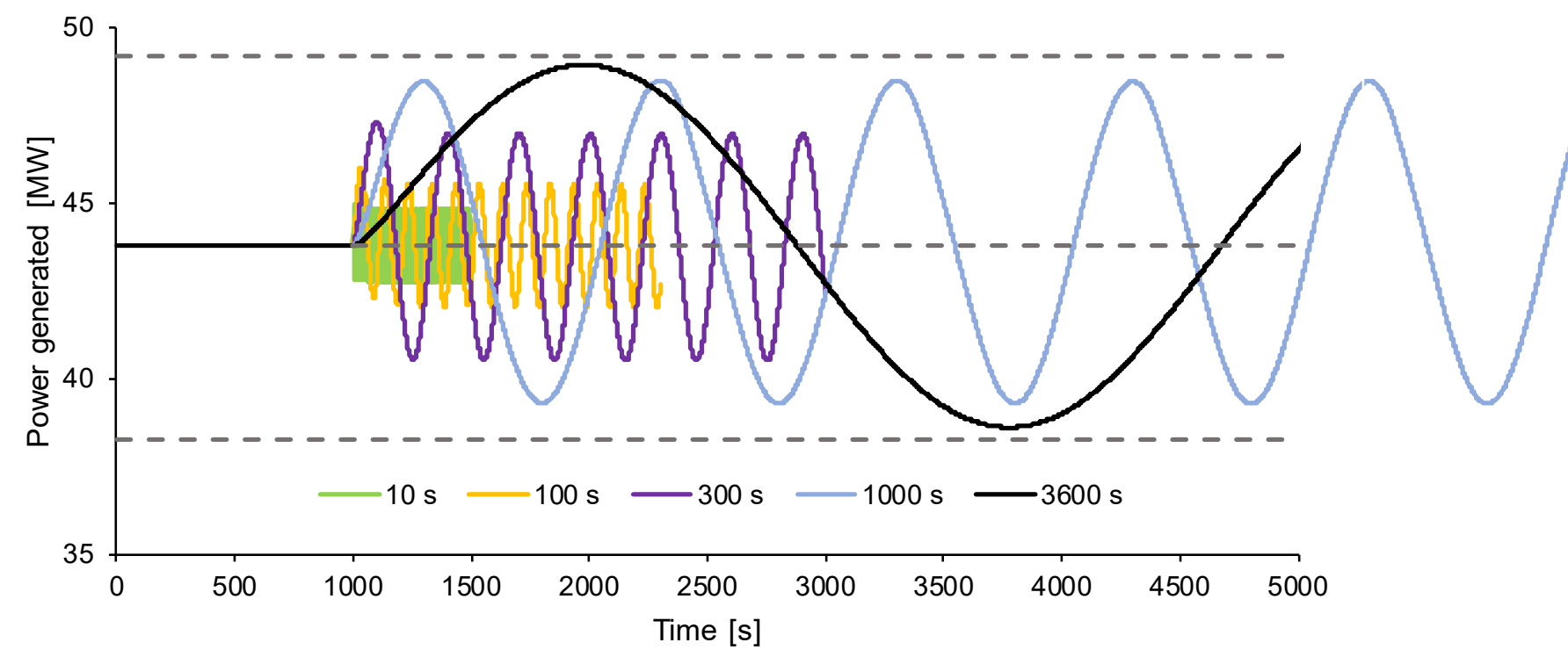

Figure 16. Responses of power generation to sinusoidal input oscillations of the boiler load, at period times of 10, 100, 300, 1000 and $3600 \mathrm{~s}$. The input oscillations start at time $1000 \mathrm{~s}$. The amplitude of the response varies with the frequency of oscillation. Dashed lines represent the offset and maximum amplitude $\left(A_{\infty}\right)$. 
Figure 17a and $\mathrm{b}$ show the relative amplitude of the process variables analyzed in Section 6.1, as a function of the period time of the sinusoidal oscillations used as inputs. For the boiler load oscillations, Figure 17a indicates that the steam cycle requires an oscillation period time of at least 1000 seconds for a significant response amplitude to occur (around 0.84). This is true for all four response variables that are studied. A period time of $1000 \mathrm{~s}$ would, for these simulations, correspond to a ramp rate of approximately $2.5 \%$ of boiler full load per minute. Further increased response amplitudes are obtained when the period time is extended to $3600 \mathrm{~s}$, with relative amplitudes of approximately 0.94 .

For the district heating input oscillations, the characteristic timescales are significantly shorter than for boiler variations, see Figure 17b, with relative amplitudes of 0.86-0.95 at a period time of $300 \mathrm{~s}$, and close to 1 at a period time of $1000 \mathrm{~s}$. However, differences in relative amplitude between the response variables are noticeable. The increase in amplitude is faster for the power production than for the DH outlet temperature, which is consistent with the results in Sections 6.1-2 concerning settling times.
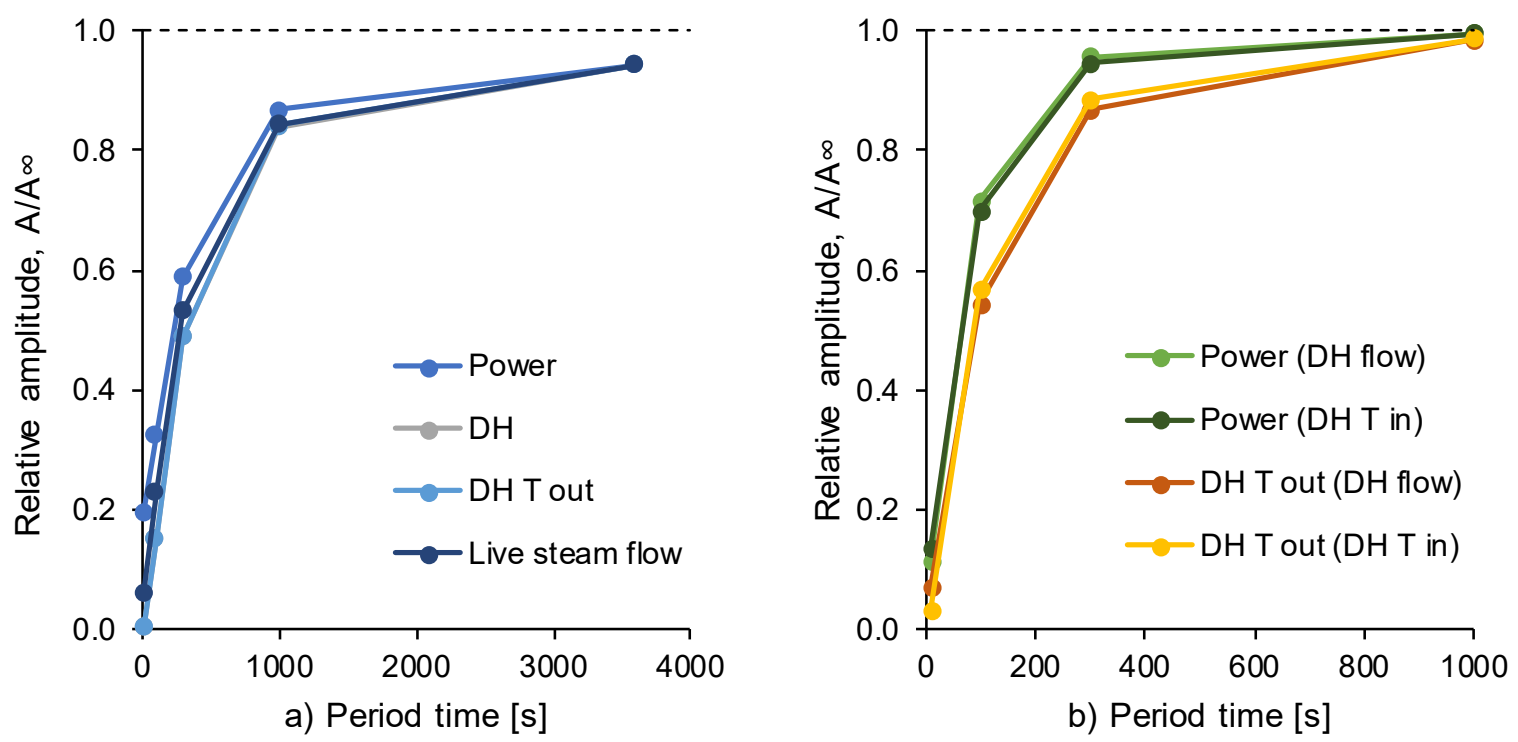

Figure 17. Relative amplitude of response variable oscillations for sinusoidal inputs to a) boiler load level, and b) district heating inlet flow and temperature. Remarks in parentheses denote the disturbance variable. Note the different time scales used on the $x$-axis.

\section{Practical implications}

This section discusses the model applicability and the practical implications on steam cycle operation, based on the simulation results presented in Section 6. The model is shown capable of qualitatively describing the steam cycle dynamics on process and component level for a broad range of operational disturbances. Possible model applications are discussed below.

The scenario with disturbances in district heating operation confirms that the district heating operation impacts the heat and power generation at the plant; the observed relative changes for a disturbance in mass flow or temperature of $10 \%$ are 1-4\% for heat and power production (Section 6.2). This is in line with previous work [61]. Nevertheless, the plant is able to maintain a stable power generation even for significant variability in $\mathrm{DH}$ conditions - up to $\pm 84 \mathrm{~kg} / \mathrm{s}$ DH flow step disturbances are studied here.

Boiler load changes affect both the DH generation and supply temperature; which is expected as the supply temperature is generally controlled by varying the boiler load. The relative changes in DH output and temperature observed are in the $4-14 \%$ span for $10 \%$ boiler load changes (Section 6.1). The impact is clear and could serve as an input to DH system studies, to quantify the importance of thermal energy storages that would allow decoupling 
of heat and power generation and enhance the flexibility of the CHP operation; or production planning studies that consider both the power market and DH demand.

The study of the DH disturbances shows that process dynamics are mainly affected by disturbances in the minutetimescale. In practice, DH input oscillations of the magnitude considered in this paper tend to be on an hourly time frame, and significant temperature variations slower yet (although this is influenced by the relative DH network size and operational strategy). For an hourly time-resolution, DH flow and temperature variations could, thus, be regarded as quasi-static and treated with sufficient accuracy by steady-state models.

Another aspect is the internal dynamics of the CHP plant steam cycle. When comparing the response times of heat and power generation for process disturbances, power output consistently has a slightly shorter settling time than DH generation. The difference between the two is, in this context, observed as being less than 3 minutes for boiler load disturbances. This implies that the inertia of the DH condensers is small, in comparison to the total inertia of the process that is found in the thermal mass of the boiler heat transfer equipment.

In terms of boiler ramping, an increment of the ramp rate from the $2 \% / \mathrm{min}$ to $4 \% /$ min gives a $42 \%$ reduction in rise time of power generation, while further increasing the ramp rate has diminishing effects. Economic incentives for faster ramping are given in [62], and could lead to an increased profit from the electricity market; for example, by taking advantage of electricity price peaks, or fuel cost savings for faster load reductions. Simulations of sinusoidal oscillations may give complimentary indications of market potential, with the dependency of relative amplitude on period time (Section 6.4). Here, load changes between $90-100 \%$ of full load require some 15 minutes for adequate power generation response. Such information could be of importance for dispatch planning, or active participation in intra-day markets.

On a component to plant level, the model can be used to obtain time constants for individual components or parts of the process, to identify bottlenecks in transient operation. New plant or component designs for increased operational flexibility can be evaluated. In addition, dynamic modeling is a powerful tool to analyze plant control schemes, e.g. sliding pressure vs valve throttling operation. Approaching the energy system level of analysis, the plant's potential to meet power market requirements for different scenarios can be simulated with the model. This is applicable to both day-ahead, intra-day and ancillary service markets and their respective demands.

\section{Conclusion}

This paper presents a dynamic model of a waste-fired combined heat and power steam cycle, based on physical equations. The model is validated with operational data for steady-state and transient operating conditions and is able to accurately predict the dynamic trends and variability within the reference plant. Scenarios for boundary condition variability (step changes, ramps and sinusoidal input oscillations for boiler load and DH flow and temperature) are studied to analyze the internal steam cycle dynamics, as well as the operational interaction between the combined heat and power plant and district heating network. The results demonstrate the model's capability to analyze process and component dynamics in combined heat and power steam cycles.

The case study of the specific CHP steam cycle gives the following characterizing findings:

- For a $10 \%$ step change in boiler load, plant settling times are within 15 minutes, while for a $10 \%$ variation in district heating flow or temperature the corresponding settling times are within 5 minutes; indicating that the main thermal inertia is found in the boiler.

- Sinusoidal simulations further differentiate the responses of boiler load and district heating variations, with characteristic timescales of $1000 \mathrm{~s}$ and $300 \mathrm{~s}$, respectively.

- Increasing the boiler ramp rate from 2 to $4 \% /$ min reduces the rise time of power generation by $42 \%$, from 12 to $6.5 \mathrm{~min}$ for a $15 \mathrm{MW}$ power reduction.

These three results are specific for the scenarios simulated here, for the $48 \mathrm{MW}$ steam cycle of a base-load wastefired CHP plant, with waste incineration as a primary objective. CHP plants of larger or smaller capacity, or other designs, may be subject to different numbers; although the general trends observed regarding dynamics, interactions and orders of magnitude, as well as the modeling approach itself, may be extrapolated to other plants. The model can thereby act as a basis for further studies of component, plant and control scheme designs; and the 
plant's potential to meet new requirements from the electricity system for which increased volatility in electricity prices can be expected.

\section{Acknowledgements}

This project is financed by the Swedish Energy Agency, Energiforsk - The Swedish Energy Research Centre and Göteborg Energi AB. The authors gratefully acknowledge the support from Solvina AB, and supply of design data and operational measurements from Mälarenergi AB, during the study.

\section{References}

[1] European Union. Energy roadmap 2050. 2012. doi:10.2833/10759.

[2] Olsson KO, Bergendahl G. Investment in Cogeneration - New Methods to Evaluate Flexibility. Gothenburg: 2006.

[3] Angerer M, Djukow M, Riedl K, Gleis S, Spliethoff H. Simulation of Cogeneration-Combined Cycle Plant Flexibilization by Thermochemical Energy Storage. J Energy Resour Technol 2017;140. doi:10.1115/1.4038666.

[4] Mollenhauer E, Christidis A, Tsatsaronis G. Increasing the Flexibility of Combined Heat and Power Plants with Heat Pumps and Thermal Energy Storage. J Energy Resour Technol 2018;140:1-13. doi:10.1115/1.4038461.

[5] Wang W, Sun Y, Jing S, Zhang W, Cui C. Improved Boiler-Turbine Coordinated Control of CHP Units with Heat Accumulators by Introducing Heat Source Regulation. Energies 2018;11:2815. doi:10.3390/en11102815.

[6] Martinez Castilla G, Biermann M, Montañés RM, Normann F, Johnsson F. Integrating carbon capture into an industrial combined-heat-and-power plant: performance with hourly and seasonal load changes. Int J Greenh Gas Control 2019;82:192-203.

[7] Kahlert S, Spliethoff H. Investigation of Different Operation Strategies to Provide Balance Energy With an Industrial Combined Heat and Power Plant Using Dynamic Simulation. J Eng Gas Turbines Power 2016;139:1-8. doi:10.1115/1.4034184.

[8] Gao Y, Hu Y, Zeng D, Liu J, Chen F. Modeling and Control of a Combined Heat and Power Unit with Two-Stage Bypass. Energies 2018;11:1395. doi:10.3390/en11061395.

[9] Anand H, Narang N, Dhillon JS. Unit commitment considering dual-mode combined heat and power generating units using integrated optimization technique. Energy Convers Manag 2018;171:984-1001.

[10] Romanchenko D, Odenberger M, Göransson L, Johnsson F. Impact of electricity price fluctuations on the operation of district heating systems: A case study of district heating in Göteborg, Sweden. Appl Energy 2017;204:16-30. doi:10.1016/j.apenergy.2017.06.092.

[11] Salman CA, Naqvi M, Thorin E, Yan J. Gasification process integration with existing combined heat and power plants for polygeneration of dimethyl ether or methanol: A detailed profitability analysis. Appl Energy 2018;226:116-28.

[12] Darabadi Zareh A, Khoskbakhti Saray R, Mirmasoumi S, Bahlouli K. Extensice thermodynamic and economic analysis of the cogeneration of heat and power system fueled by the blend of natural gas and biogas. Energy Convers Manag 2018;164:329-43. doi:10.1016/j.enconman.2018.03.003.

[13] Alobaid F, Mertens N, Starkloff R, Lanz T, Heinze C, Epple B. Progress in dynamic simulation of thermal power plants. Prog Energy Combust Sci 2017;59:79-162. doi:10.1016/j.pecs.2016.11.001.

[14] Angerer M, Kahlert S, Spliethoff $\mathrm{H}$. Transient simulation and fatigue evaluation of fast gas turbine startups and shutdowns in a combined cycle plant with an innovative thermal buffer storage. Energy 
2017;130:246-57. doi:10.1016/j.energy.2017.04.104.

[15] Stoppato A, Mirandola A, Meneghetti G, Lo Casto E. On the operation strategy of steam power plants working at variable load: Technical and economic issues. Energy 2012;37:228-36. doi:10.1016/j.energy.2011.11.042.

[16] Benato A, Stoppato A, Mirandola A, Destro N, Bracco S. Superheater and Drum Lifetime Estimation : An Approach Based on Dynamic Analysis. J Energy Resour Technol 2018;139:1-7. doi:10.1115/1.4035020.

[17] Farragher TP, Scully S, O’Dowd NP, Leen SB. Development of life assessment procedures for power plant headers operated under flexible loading scenarios. Int J Fatigue 2013;49:50-61. doi:10.1016/j.ijfatigue.2012.12.007.

[18] Chen C, Zhou Z, Bollas GM. Dynamic modeling, simulation and optimization of a subcritical steam power plant. Part I: Plant model and regulatory control. Energy Convers Manag 2017;145:324-34. doi:10.1016/j.enconman.2017.04.078.

[19] Chen C, Bollas GM. Dynamic Optimization of a Subcritical Steam Power Plant Under Time-Varying Power Load. Processes 2018;6:114. doi:10.3390/pr6080114.

[20] Oko E, Wang M. Dynamic modelling, validation and analysis of coal-fired subcritical power plant. Fuel 2014;135:292-300. doi:10.1016/j.fuel.2014.06.055.

[21] Liang XU, Jingqi Y. Dynamic Modeling and Validation of the Boiler-side Whole Process of Subcritical Coal-fired Power Plants. Proc 34th Chinese Control Conf 2015:2093-8.

[22] M. Montañés R, GarĐarsdóttir SÓ, Normann F, Johnsson F, Nord LO. Demonstrating load-change transient performance of a commercial-scale natural gas combined cycle power plant with postcombustion CO2 capture. Int J Greenh Gas Control 2017;63:158-74. doi:10.1016/j.ijggc.2017.05.011.

[23] Wellner K, Marx-schubach T, Schmitz G. Dynamic Behavior of Coal-Fired Power Plants with Postcombustion CO2 Capture. Ind Eng Chem Res 2016;55:12038-45. doi:10.1021/acs.iecr.6b02752.

[24] Gardarsdóttir S, Montañés RM, Normann F, Nord LO, Johnsson F. Effects of CO2-Absorption Control Strategies on the Dynamic Performance of a Supercritical Pulverized-Coal-Fired Power Plant. Ind Eng Chem Res 2017;56:4415-30. doi:10.1021/acs.iecr.6b04928.

[25] Nord LO, Montañés RM. Compact steam bottoming cycles: Model validation with plant data and evaluation of control strategies for fast load changes. Appl Therm Eng 2018;142:334-45.

[26] Montañés RM, Windahl J, Pålsson J, Thern M. Dynamic Modeling of a Parabolic Trough Solar Thermal Power Plant with Thermal Storage Using Modelica. Heat Transf Eng 2018;39:277-92. doi:10.1080/01457632.2017.1295742.

[27] Alobaid F, Starkloff R, Pfeiffer S, Karner K, Epple B, Kim HG. A comparative study of different dynamic process simulation codes for combined cycle power plants-Part A: Part loads and off-design operation. Fuel 2015;153:692-706. doi:10.1016/j.fuel.2015.02.010.

[28] Zhao Y, Wang C, Liu M, Chong D, Yan J. Improving operational flexibility by regulating extraction steam of high-pressure heaters on a $660 \mathrm{MW}$ supercritical coal-fired power plant: A dynamic simulation. Appl Energy 2018;212:1295-309. doi:10.1016/j.apenergy.2018.01.017.

[29] Zhao Y, Liu M, Wang C, Li X, Chong D, Yan J. Increasing operational flexibility of supercritical coalfired power plants by regulating thermal system configuration during transient processes. Appl Energy 2018;228:2375-86. doi:https://doi.org/10.1016/j.apenergy.2018.07.070.

[30] Li D, Wang J. Study of supercritical power plant integration with high temperature thermal energy storage for flexible operation. J Energy Storage 2018;20:140-52. doi:10.1016/j.est.2018.09.008. 
[31] Korpela T, Kaivosoja J, Majanne Y, Laakkonen L, Nurmoranta M, Vilkko M. Utilization of District Heating Networks to Provide Flexibility in CHP Production. Energy Procedia 2017;116:310-9. doi:10.1016/j.egypro.2017.05.077.

[32] Alobaid F, Al-Maliki WAK, Lanz T, Haaf M, Brachthäuser A, Epple B, et al. Dynamic simulation of a municipal solid waste incinerator. Energy 2018;149:230-49. doi:10.1016/j.energy.2018.01.170.

[33] Zimmerman N, Kyprianidis K, Lindberg C-F. Waste Fuel Combustion : Dynamic Modeling. Processes 2018;6:222. doi:10.3390/pr6110222.

[34] Seborg DE, Edgar TF, Mellichamp DA, Doyle FJ. Process Dynamics and Control. 3rd ed. John Wiley \& Sons; 2011.

[35] Shin JY, Jeon YJ, Maeng DJ, Kim JS, Ro ST. Analysis of the dynamic characteristics of a combinedcycle power plant. Energy 2002;27:1085-98.

[36] Dymola Systems Engineering n.d. https://www.3ds.com/products-services/catia/products/dymola/.

[37] Modelica and the Modelica Association n.d. https://www.modelica.org/.

[38] Modelon Thermal Power Library n.d. https://www.modelon.com/library/thermal-power-library/.

[39] Dechamps P. Modelling the transient behaviour of heat recovery steam generators. Proc Inst Mech Eng Part A J Power Energy 1995;209:265-73.

[40] Montañés RM. Transient performance of combined cycle power plant with absorption based postcombustion $\mathrm{CO} 2$ capture: dynamic simulations and pilot plant testing ( $\mathrm{PhD}$ Thesis). Norwegian University of Science and Technology, 2018.

[41] VDI-Wärmeatlas, 9th Edition, section Gg. 9th ed. Springer; 1997.

[42] Majanne Y, Köykkä P. Dynamic Model of a Circulating Fluidized Bed Boiler. IFAC Proc. Vol., 2009, p. 255-60. doi:10.3182/20090705-4-SF-2005.00046.

[43] Starkloff R, Alobaid F, Karner K, Epple B, Schmitz M, Boehm F. Development and validation of a dynamic simulation model for a large coal-fired power plant. Appl Therm Eng 2015;91:496-506. doi:10.1016/j.applthermaleng.2015.08.015.

[44] Bhambare KS, Mitra SK, Gaitonde UN. Modeling of a Coal-Fired Natural Circulation Boiler. J Energy Resour Technol 2007;129:159. doi:10.1115/1.2719209.

[45] Liu H, Hibiki T. Flow regime transition criteria for upward two-phase flow in vertical rod bundles. Int $\mathbf{J}$ Heat Mass Transf 2017;108:423-33. doi:10.1016/j.ijheatmasstransfer.2016.12.029.

[46] Åström K., Bell R. Drum-Boiler Dynamics. Automatica 2000;36:363-78.

[47] Eborn J. On Model Libraries for Thermo-hydraulic Applications (PhD Thesis). Lund Institute of Technology (LTH), 2001.

[48] Cooke DH. On Prediction of Off-Design Multistage Turbine Pressures by Stodola's Ellipse. Trans ASME 1985;107:596-606.

[49] Beebe R. Condition monitoring of steam turbines by performance analysis. J Qual Maint Eng 2003;9:102-12. doi:10.1108/13552510310482361.

[50] Bolland O. Thermal power generation 2014:1-176.

[51] Paranjape R. Modeling and control of a supercritical coal fired boiler (PhD Thesis). Texas Tech University, Lubbock, TX, 1996.

[52] Heat Exchange Institute. Condenser hotwells 2015:1-3. www.heatexchange.org. 
[53] VDI-Wärmeatlas, 9th Edition, section Ja 7. 9th ed. Springer; 1997.

[54] Dzodzo MB, Liu B, Cionocolini A, Spiegelman SR. Application of CFD for Modeling Flows in FeedWater Pipelines. 14th Int. Conf. Nucl. Eng., 2006, p. 293-301. doi:10.1115/ICONE14-89549.

[55] The Babcock \& Wilcox Company. Steam: Its generation and use, Chapter 41. 41st ed. The Babcock \& Wilcox Company; 2005.

[56] Skogestad S. Probably the best simple PID tinung rules in the world. AIChE Annu. Meet., Reno, USA: 2001.

[57] Aske EMB, Skogestad S. Consistent Inventory Control 2009:10892-902.

[58] Gabrielaitiene I, Bohm B, Sundén B. Dynamic temperature simulation in district heating systems in Denmark regarding pronounced transient behaviour. J Civ Eng Manag 2011;17:79-87. doi:10.3846/13923730.2011.553936.

[59] Larsson G. Dynamik i fjärrvärmesystem (PhD Thesis). Chalmers University of Technology, 1999.

[60] Montañés RM, Flø NE, Nord LO. Dynamic Process Model Validation and Control of the Amine Plant at CO2 Technology Centre Mongstad. Energies 2017;10:1527. doi:10.3390/en10101527.

[61] Savola T, Keppo I. Off-design simulation and mathematical modeling of small-scale CHP plants at part loads. Appl Therm Eng 2005;25:1219-32. doi:10.1016/j.applthermaleng.2004.08.009.

[62] Haynes CJ, Koch J. How to determine a unit ramp rate (MW/min) for lowest total production cost. 1987:1-13. http://heatrate.com/tech.php. 